\title{
Photonics of human saliva: potential optical methods for the screening of abnormal health conditions and infections
}

\author{
Jijo Lukose ${ }^{1}$ - Sanoop Pavithran M. ${ }^{1}$ - Mithun N. ${ }^{1}$ Ajaya Kumar Barik ${ }^{1}$ - Keerthilatha M. Pai ${ }^{2}$ V. K. Unnikrishnan ${ }^{1}$. \\ Sajan D. George ${ }^{3} \cdot$ V. B. Kartha ${ }^{1} \cdot$ Santhosh Chidangil ${ }^{1}$ (it)
}

Received: 10 February 2021 / Accepted: 7 May 2021 / Published online: 2 June 2021

(C) The Author(s) 2021

\begin{abstract}
Human saliva can be treated as a pool of biological markers able to reflect on the state of personal health. Recent years have witnessed an increase in the use of optical devices for the analysis of body fluids. Several groups have carried out studies investigating the potential of saliva as a non-invasive and reliable clinical specimen for use in medical diagnostics. This brief review aims to highlight the optical technologies, mainly surface plasmon resonance (SPR), Raman, and Fourier transform infrared (FTIR) spectroscopy, which are being used for the probing of saliva for diverse biomedical applications. Advances in bio photonics offer the promise of unambiguous, objective and fast detection of abnormal health conditions and viral infections (such as COVID-19) from the analysis of saliva.
\end{abstract}

Keywords Photonics $\cdot$ Saliva $\cdot$ COVID-19 $\cdot$ SPR $\cdot$ Raman spectroscopy $\cdot$ SERS $\cdot$ FTIR $\cdot$ HPLC-LIF

\section{Introduction}

Here we review well-recognized photonics-based technologies, surface plasmon resonance (SPR), Raman, and Infrared spectroscopy, which are being used currently for analysing clinical samples like body fluids (saliva, blood, urine and vaginal wash), biopsy tissue samples, and cellular samples in diverse biomedical applications, and discuss how these photonics-based methods applied to saliva can be a highly promising technology for universal screening in situations like the present COVID-19 pandemic.

Santhosh Chidangil

santhosh.cls@manipal.edu

1 Centre of Excellence for Biophotonics, Department of Atomic and Molecular Physics, Manipal Academy of Higher Education, Manipal, Karnataka 576104, India

2 Department of Oral Medicine and Radiology, Manipal College of Dental Sciences, Manipal, Manipal Academy of Higher Education, Manipal, Karnataka 576104, India

3 Centre for Applied Nanoscience, Department of Atomic and Molecular Physics, Manipal Academy of Higher Education, Manipal, Karnataka 576104, India

\section{Photonics-based technologies and their significance}

Though photonics techniques can involve the entire range of the electromagnetic spectrum-from gamma rays to microwaves (wavelengths of fraction of a nanometer to several cms)-current interest on bio-medical applications is mostly centred in the UV-Visible-Infra red region, covering optical radiation in the range of a few hundred nanometres to about a hundred microns $\left(10^{6}\right.$ to $10^{2} \mathrm{~cm}^{-1}$ (wave numbers)), and we will cover only this range in the present review. Powerful portable/miniature radiation sources like tunable lasers, super radiant light sources, light-emitting diodes (LEDs), and laserdriven light sources (LDLSs) are now commercially available. New techniques like broadband optical coherent emission has also been shown to be capable of direct IR spectra measurement, opening up possibility of broadband infrared spectroscopic study of samples with sensitivity down to submicrograms/ millilitre in samples like serum (Pupeza et al. 2020).

Till a little more than a decade back, spectroscopic systems involved relatively large instrumentation, making them amenable to only lab-based operation. Miniature spectrometers are now available as off-the-shelf units. Portable/handheld spectroscopic/photonics-based instrumentation, like mobilephone-based examination systems, are available now Also 
optical fibre technologies have transformed telecommunication by enabling big data transfer with reduced latency. These advances have facilitated the use of photonics-based instrumentation by trained technicians, for survey of cases in "As Is, Where Is" conditions, and transmission of the data to centrally located facilities with qualified medical professionals for decision making (Cai et al. 2017; Rani et al. 2019; Ko et al. 2020; Pal et al. 2020). The combination of miniature systems, like mini-detectors with mini-spectrometers have made it possible at present to use of techniques like multi-directional functional spectroscopy systems for imaging applications on proof of concept (POC) basis (Shimokawa et al. 2019). Combination of these advances in instrumentation, data transmission and data processing, with artificial intelligence (AI) and machine learning (ML) processes have made photonicsbased technologies easily adaptable for universal health-care applications, involving large population groups spread across several location (Belushkin et al. 2020; Nogueira 2020).

Optical spectroscopy techniques have proved to be of great utility in providing novel solutions in many clinical needs (AlMuslet and Ali 2011; Popp et al. 2011; Spyratou et al. 2012; Krafft 2016; Cordero et al. 2018; Wallace 2019). These include, the use of optical coherence tomography in ophthalmic care, photonics based medical imaging for preclinical research, Raman, fluorescence and other spectroscopic studies of clinical samples, and observation of disease-specific markers at ultra-trace levels, all of which allow regular screening, early detection, tracking and follow-up in many diseases, both communicable and non-communicable. Contactless, non-invasive photonic-based wearable sensors, which can provide rapid, and precise health information are also becoming common-place now (Yang and Gao 2019). Most important, photonics-based methods like Laser-induced fluorescence -LIF-, laser raman spectroscopy, photo thermal spectroscopy, hyperspectral imaging, laser-induced breakdown spectroscopy (LIBS), and reflectance spectroscopy are capable of remote, non-contact observation, and hence are highly suitable for identification of harmful or abnormal conditions in any kind of samples, including, clinical, environmental, and other (e.g., human and animal subjects) samples by remote, non-contact observations (Shameem et al. 2017; Bishop et al. 2019; Gabbarini et al. 2019; Mandrile et al. 2019; Nganou et al. 2019; Yeh et al. 2020).

\section{Potential of saliva as a unique clinical specimen}

Saliva is a transparent hypotonic aqueous solution produced by the salivary glands (Fig. 1). It acts as a detergent of the teeth and oral cavity, and as a lubricant for food ingestion. A healthy adult produces $\sim 600 \mathrm{ml}$ saliva in a day, having a pH range 6.6-7.1 (Zhang et al. 2016).
Around $99 \%$ of saliva comprises of water and a variety of inorganic ions (e.g. $\mathrm{K}^{+}, \mathrm{Na}^{+}, \mathrm{Ca}^{2+}, \mathrm{Mg}^{2+}, \mathrm{Cl}^{-}$, $\mathrm{HCO}_{3}{ }^{-}, \mathrm{H}_{2} \mathrm{PO}_{4}^{-}, \mathrm{HPO}_{4}{ }^{2-}$ ), proteins (immunoglobulins, enzymes), mucus, urea, and uric acid forming the remaining portion (Bonifacio et al. 2015). In addition, more than 700 microorganisms have also been reported in saliva which can be linked with oral health and other systemic diseases (Zhang et al. 2016). It has been suggested that the human oral microbiome contributes more than 2000 microbial proteins from more than fifty bacterial genera to the saliva proteome (Katsani and Sakellari 2019). Salivary biomarkers have been suggested as highly suitable for regular screening and early detection of many abnormal conditions (Farah et al. 2018; Liu et al. 2018; Shah 2018; Gug et al. 2019; Pathiyil and Udayasankar 2019).

The growing appeal in saliva research for clinical applications has resulted in the appearance of various devices in market which facilitates both sterile and safer saliva collection (Khurshid et al. 2016) Non-invasive screening and early diagnosis of diseases, especially viral infections, from human saliva utilizing optical tools can be a reliable option for mass screening, especially in situations like COVID-19, where sampling and analysis of several hundreds of samples will be required fast with minimum contact with the subjects/sample. Unlike blood and throat swab, saliva is easier to collect, store and transport (Wang et al. 2016; Ilea et al. 2019). Sample collection procedure does not demand the requirement of an expert in phlebotomy as in case of blood collection (Azzi et al. 2020). This can also minimize the risk of exposing health/social workers to blood-borne diseases (Kaczor-Urbanowicz et al. 2017). Since the sample collection procedure is painless, it will be more acceptable for haemophiliacs, neonates, elderly, and disabled people (Guilbault et al. 1995; Malon et al. 2014). This will be also an added advantage in increasing the compliance/cooperation from the suspected/vulnerable cases who need recurrent clinical monitoring via multiple sampling over the day or several days. Self-collection of samples by vulnerable subjects itself can undo direct interaction between patient and healthcare worker, which can be the primary risk factor for nosocomial infections (To et al. 2019; Ceron et al. 2020).

In this review, we will try to cover the various photonics tools which can be used for probing saliva samples. Being label free and highly sensitive tools, the core part of the review is confined to the studies regarding the exploration of plasmonic, infrared, raman, and laser-induced fluorescence approaches for the analysis of salivary fluids. In the current threatening pandemic scenario, it may be highly useful if the many research centres, health agencies, and health care providers explore the various photonics-based diagnostics opportunities which can lead to fast, universal screening and detection techniques. 


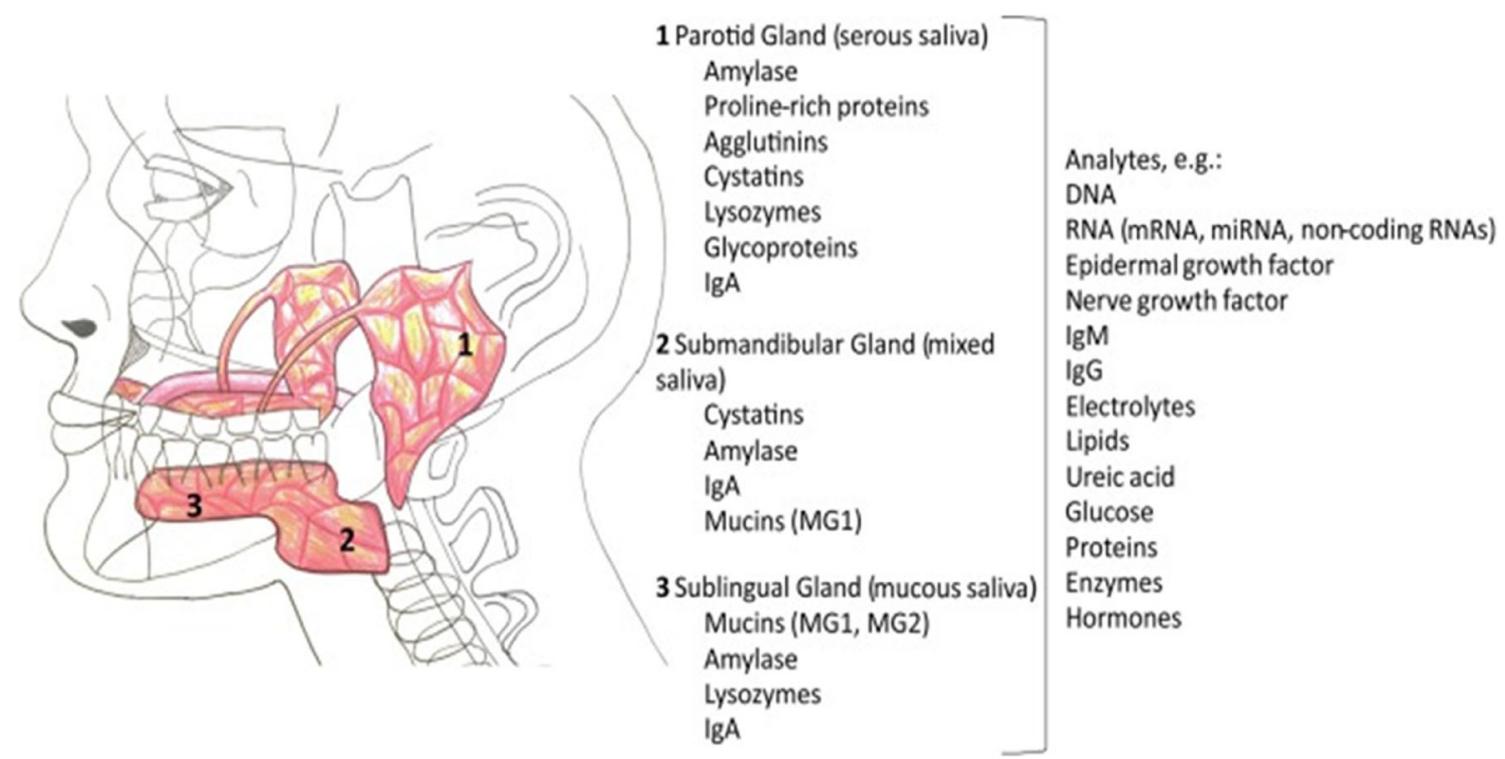

Fig. 1 Schematic illustration of the major salivary glands and their contributions to the components of saliva. Reprinted with permission from (Roblegg et al. 2019)

\section{Optical spectroscopy techniques for saliva}

\section{Surface plasmon resonance}

Surface plasmon resonance technique has received much attention recently for biomedical applications, owing to its high sensitivity. The technique offers label free detection of biological analytes without the requirement of any fluorescing or radioactive tags. Surface plasmons are guided electron oscillations confined to a thin layer of a metal-dielectric interface (Liedberg et al. 1995). Excitation of surface plasmons can be realized using an incident radiation, once the optical wave vector parallel to the interface matches the wave vector of surface plasmon. Under optimal conditions, optically excited surface plasmon resonance (SPR) could be quite strong and a large portion of optical energy is dissipated into a guided electromagnetic wave along the interface leading to absorption of energy. As the extent of energy transfer is highly sensitive to the coupling conditions, parameters like the refractive index of the dielectric layer can be accurately determined by monitoring the reflected light intensity or phase, which can be explored for various bio-sensing applications (Homola 2003; Homola and Piliarik 2006; Lukose et al. 2016; Lukose et al. 2018). Adsorption of any target sample on the sensor surface using surface functionalized receptors can induce a refractive index variation, which can be identified by tracking the change in the conditions of the resonance coupling of incident light to the propagating surface Plasmon wave (SPW). Resonance coupling can be identified by a dip in the reflectivity of the light spectrum, which is traditionally tracked by measuring the wavelength, the incident angle or the intensity of the reflected light.
Recently this technique has been employed to study the interaction between ACE-2 receptor and spike glycoprotein of coronavirus (SARS-COV, SARS-COV-2, MERS-COV) (Shang et al. 2020; Wang et al. 2020). SARS-COV-2 have shown comparatively higher binding affinity towards ACE-2 receptor as per the SPR sensorgram results. Highly localized effect is observed, once the plasmonic resonance is restricted to a nanomaterial surface instead of a planar substrate, leading to a non-propagating localized surface plasmon with a specific frequency, which is termed as localized surface plasmon resonance (LSPR) (Fig. 2a) ( Wang et al. 2020). Plasmonic-based sensors have also been widely exploited for the detection of analytes in human saliva and to monitor the interactions of salivary proteins.

LSPR has been used to study cortisol (indicator for stress), Cathepsin and Mucin (Fernández-González et al. 2007; Stevens et al. 2008; Frasconi et al. 2009; Mitchell et al. 2009; Gorodkiewicz and Regulska 2010; Gorodkiewicz et al. 2011; Tahara et al. 2014; Jo et al. 2020). Gorodkiewicz et al have conducted Cathepsin $\mathrm{G}(\mathrm{CatG})$ detection in saliva using a custom built SPR imaging instrument (Gorodkiewicz et al. 2011). Perturbations of CatG activity in saliva have a critical role in the pathobiochemistry and diagnostics of salivary gland, gingiva, and oral mucosa diseases (Ozmeric 2004). SPR imaging (SPRi) technique has been employed for the determination of cystatin (a marker for chronic renal failure) in human body fluids such as plasma, urine and saliva (Gorodkiewicz and Luszczyn 2011; Alsamarai et al. 2018). LSPR has also been used for the detection of drugs - cocaine, MDMA (3,4-methylenedioxymethamphetamine) and fenetoyin in saliva (Liu and Delgado 1999; Fu et al. 2007; Sonny et al. 2010). Simple laboratory-built LSPR systems 
Fig. 2 A) Prism coupling configuration of SPR, where a light beam impinges on a thin metallic film deposited on a prism. P-polarized light absorbed by the surface plasmon is seen from a minimum in the reflection spectra. B) Representation of the localized surface plasmon on nanoparticles and absorbance spectra obtained for binding events on nanoparticles. Reproduced from (Masson 2020) with permission from The Royal Society of Chemistry. (b) SPRi instrument developed for biosensing. Reproduced from (Lukose et al. 2018)

\begin{abstract}
(a)
\end{abstract}
SPR

(b)

LSPR
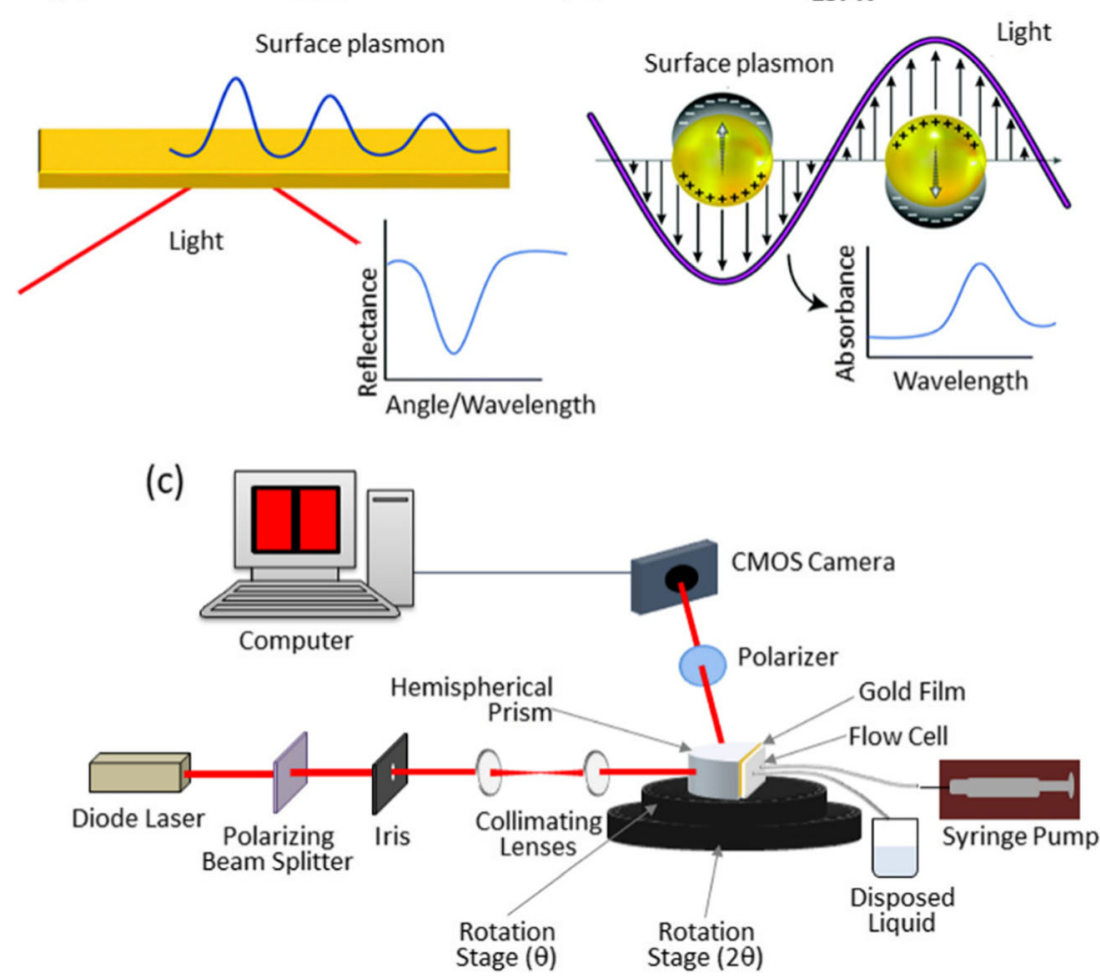

(Fig. 2.b) have been used for real-time, rapid detection of various biomolecules and pathogens (Lukose et al. 2016).

Peungthum et al. have combined SPR imaging with antibody array method for the quantitative detection of $\mathrm{ABH}$ antigens in saliva (Peungthum et al. 2017). As given in the Fig. 3 , a multiplex format consisting of an antibody array with immobilized anti-A, anti-B and anti-H on the hydrogelcoated surface was developed to specifically quantify A, B and $\mathrm{H}$ substances simultaneously. A sandwich assay with a mixture of anti-A, anti-B and anti-H antibodies was developed to increase sensitivity. The assay demonstrated good specificity and precision when diluting saliva specimens (Fig. 3). SPR technique using sandwich immunoassay has shown high specificity is less complicated than the usual neutralization agglutination test which demands skilled personal, is time consuming, and susceptible to operator interpretation error. Musso et al. have coupled SPRi with mass spectrometry for the analysis of protein biomarkers in human saliva (Musso et al. 2015). SPR technique has been used to monitor the kinetic interactions between Porphyromonas gingivalis fimbriae and various salivary proteins in comparison with haemoglobin and fibrinogen (Amano et al. 1999). Guerreiro et al have a developed a biosensor comprising SPR and molecular imprinted polymers (MIP) for evaluating the interactions between saliva and polyphenol compounds for wine astringency estimation (Guerreiro et al. 2017). The astringency obtained using this technique over a range of wine samples have shown good correlation with the values estimated from a trained sensorial panel, which suggests the utility of this method as a quantitative approach during wine production.

Researchers have also used LSPR technique to monitor the salivary $\mathrm{pH}$ (Luo et al. 2017). Saliva $\mathrm{pH}$ is an indicator for evaluating oral health conditions as well as diseases such as mucosal stomatitis which show lower $\mathrm{pH}$ value. Some of the drug activities also relies on $\mathrm{pH}$ of saliva. Yang et al. have performed quantitative measurements of interleukin- 8 (IL-8) protein in saliva in view of reports about the potential of salivary IL-8 level as a biomarker for oropharyngeal squamous cell carcinoma (OSCC) (Yang et al. 2005). Liang et al. have demonstrated the detection of carbohydrate antigen 15-3 (CA15-3), a biomarker for the early detection of breast cancer, in saliva (Liang et al. 2012). In another study, SPR method was utilized for matrixmetalloproteinase-9 (MMP-9) detection, which is of interest in chronic periodontitis (CP) disease. High levels of MMP-9 (above $20 \mathrm{ng} / \mathrm{ml}$ ) in human saliva can be an indicator for CP condition (Isaza-Guzmán et al. 2011). MMP-9 detection with an LOD of $8 \mathrm{pg} / \mathrm{ml}$ was achieved using anti-MMP-9 immobilized on carboxymethyldextran (CM-5) sensor chip. Concentration of MMP in saliva collected from normal subjects were found to be lower than those of periodontitis patients, as was seen from the SPR measurements (Mohseni et al. 2016). Using aptamer functionalized surfaces, SPR biosensor has been used for detection of avian influenza virus in poultry swab samples of saliva in the range of concentrations 0.128 to $12.8 \mathrm{HAU}$ (haemagglutination units) (Bai et al. 2012). Dostalek et al. have developed a novel plasmonic 
Fig. 3 (a) SPR procedure for $\mathrm{ABH}$ antigen detection in saliva. (b, c) SPR sensorgrams of ABH antigen detection in red blood cells (direct assay) (b) and saliva (sandwich assay) (c). Reproduced from Ref. (Peungthum et al. 2017)
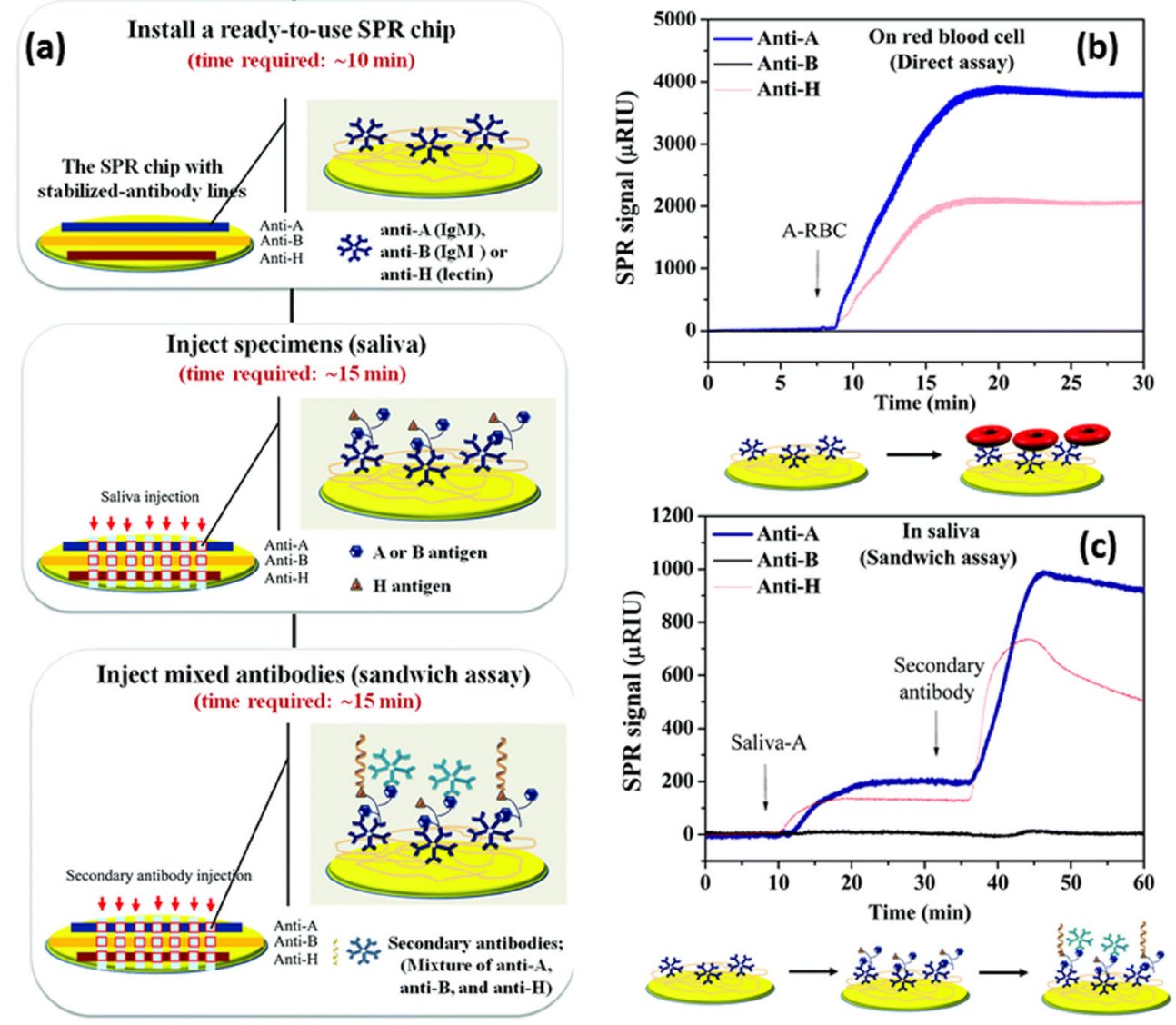

enhanced fluorescence biosensor for the hepatitis B detection from saliva samples (Riedel et al. 2017). Anti-HBs antibodies from clinical samples was detected using the combination of angular interrogation SPR and plasmonically enhanced fluorescence (Fig. 4). The sensor response obtained for saliva collected from volunteers who showed positive (saliva A) and negative response (saliva F) during ELISA test of serum samples is given in Fig. 4(b).

\section{Raman and IR spectroscopy}

Vibrational spectroscopic techniques, infra-red (IR) absorption/reflection, and Raman scattering, depend on the interaction of electromagnetic radiation with the dipole moment or polarizability, respectively, of a molecule, leading to changes in the vibrational-rotational energy states. This interaction between the radiation and molecular species is measured by observing the changes in the spectral distribution of the incident radiation in the interaction, namely absorption or scattering. In IR spectroscopy one usually measures the absorption or reflection of mid Infrared radiation by the sample. In Raman scattering, the sample is excited with radiation at a chosen wavelength and the spectral distribution of the scattered radiation is measured to determine the energy lost/ gained from vibrational energy level changes during the interaction. The basic schematic diagram of Raman scattering and IR absorption is depicted in Fig. 5.

Since the energy levels of a molecule are determined by the structure of the molecule, which are highly specific for the molecule concerned, information on the individual molecules and their amounts present in the sample can be derived from IR and Raman spectra. Advances in instrumentation, radiation sources, and data processing techniques at present, have made these techniques capable of fast, routine measurements on many types of samples. Moreover, the non-destructive nature of the technique and the requirement of only micro amounts of samples have made these techniques highly useful for clinical applications (Baker and Faulds 2016).

\section{Raman spectroscopy of saliva}

Raman spectroscopy of clinical samples like body fluids (e.g., blood, saliva, urine), biopsy tissue and cellular samples can provide information about the sample, highly useful in clinical diagnostics, pharmaceutical sciences, drug abuse and forensic applications (Sikirzhytski et al. 2012; Han et al. 2015; Zapata et al. 2015; Bunaciu et al. 2017; Parlatan et al. 2019). Raman spectroscopic investigations of saliva samples for forensic purposes have been reported by a number of groups. Differentiation of body fluids such as peripheral blood, saliva, 
Fig. 4 (a). Schematics of plasmon-enhanced fluorescence spectroscopy biosensor with a detail of sensor chip with poly(HPMA-co-CBMAA) brush functioning as a binding matrix. (b). Example of kinetics of fluorescence signal for negative and highly positive saliva samples. Reproduced under a Creative Commons Attribution (CC-BY) License from (Riedel et al. 2017)

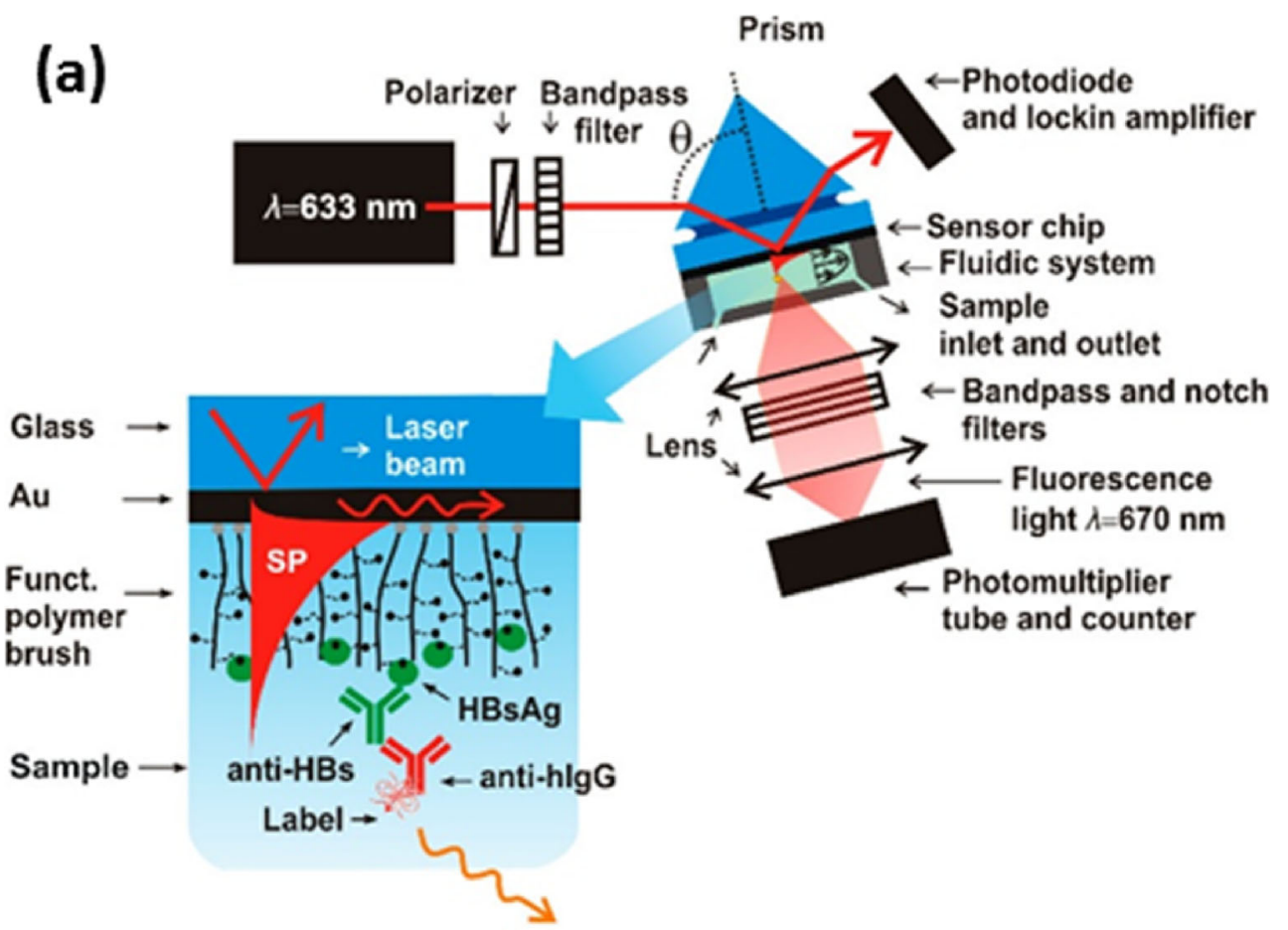

Fluorescence

light $\lambda=670 \mathrm{~nm}$

(b)

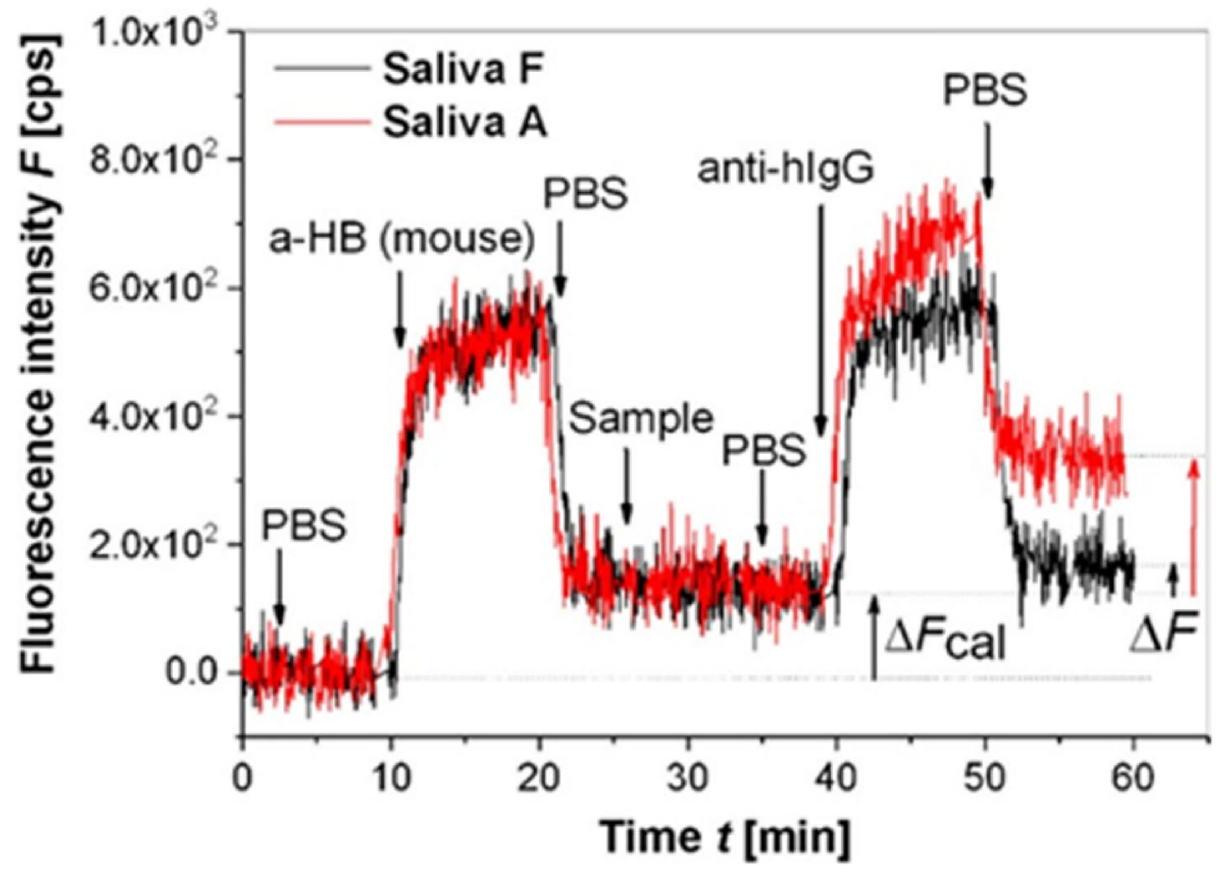

semen, sweat, and vaginal fluid has been demonstrated with $\sim 100 \%$ accuracy by using multivariate analysis of the Raman spectroscopy data (Muro et al. 2016a, 2016b). Sex determination from dry saliva has been performed with more than $90 \%$ accuracy (Muro et al. 2016a, 2016b). In a similar work, the spectra of dried saliva obtained from multiple donors have shown consistent bands derived from proteins, an acetate, a saccharide, and the amino acid, arginine (Virkler and Lednev 2010).

The inherent low cross-sections for Raman scattering have somewhat restricted its use for clinical applications requiring trace detection and high sensitivity. However, this drawback 
can be overcome with the use of two special techniques, surface enhanced Raman scattering (SERS), and resonance Raman scattering (RRS), which provide signal enhancement by several orders of magnitude. SERS is capable of detection down to single molecule levels (enhancement of intensities to even by an order of $10^{14}$ ), while resonance Raman has been reported to give enhancements up to $10^{6}$ times the signal observed in conventional Raman spectroscopy, due to both the resonance effect, and the dependence of scattering cross sections on $1 / \lambda^{4}$, where $\lambda$ is the excitation wavelength (Langer et al. 2019). The resonance Raman spectra, especially for molecules like proteins, and nucleic acids are observed at wavelengths of the order of $250 \mathrm{~nm}$, while conventional Raman for biological systems uses NIR (>750nm) excitation to avoid strong background fluorescence (Kneipp et al. 1998; Wood et al. 2005; Tuschel 2018).

SERS has been used for the identification of drugs in saliva. Dana et al. used gold and silver sol gels as SERS probes to detect cocaine in saliva at clinical concentrations, as low as 25 $\mathrm{ng} / \mathrm{ml}$ (Dana et al. 2015). SERS technique using metal-doped sol-gels was employed for the identification of drugs as well as metabolites (caffeine, phenobarbital, cocaine, amphetamine, diazepam, methadone, and 1-(1-phenylcyclohexyl) piperidine (PCP)) present in human saliva (Shende et al. 2005; Inscore et al. 2011). Magnetic assay-based SERS technique was also reported, in which Au nanoparticles-doped magnetic nanocomposites (AMN), modified with inositol hexakisphosphate substrate, was used for generating enhanced Raman signal of trace amounts of drug-related biomarkers in saliva (Yang et al. 2015). Magnetically induced SERS assay have displayed two Raman bands at $1030 \mathrm{~cm}^{-1}$ and $1052 \mathrm{~cm}^{-1}$ for cotinine in saliva, whereas only a weak band at $1030 \mathrm{~cm}^{-1}$ was observed in routine SERS assay. SERS technique was also adopted for developing portable/ field usable devices for the detection of illicit drug presence (diazepam) in saliva in $\sim 15 \mathrm{~min}$ (Shende et al. 2014). SERS strips which can be inserted into a portable Raman spectrometer have been used in field applications for the rapid measurement of codeine and fentanyl in saliva (Shende et al. 2019). SERS measurements conducted on a group of narcotic users have displayed an additional band at $1030 \mathrm{~cm}^{-1}$ in their saliva with respect to non-narcotic users (Anyu et al. 2009). Quantitative measurement of heroin, morphine monohydrate $(\mathrm{MM})$, morphine-3- $\beta$-glucuronide (M3B), and monoacetyl morphine (6MAM) in saliva samples using SERS was reported recently (Akçan et al. 2020). SERS detection of trace levels of cocaine in raw saliva was achieved without any sample preprocessing. Inscore et al. studied identification of certain illicit drugs in saliva with SERS, including heroin, without measuring their concentrations (Farquharson et al. 2011; Inscore et al. 2011). Andreou et al have performed the detection of illicit drugs in saliva with a micro-fluidic device, which exploits the SERS technique induced by the aggregation of AgNPs as shown in Figure 6. (Andreou et al. 2013). A laminar flow composing a stream of methamphetamine along with two sheath streams of salt solutions and AgNPs were produced inside the channel. At the interrogation region, SERS-active nanoparticle dimers and small-order aggregates with methamphetamine predominantly formed. Due to the low affinity of methamphetamine to the silver nanoparticles, the salt was added to induce the aggregation. Trace concentrations of methamphetamine in saliva were detected within minutes. The microfluidic sensor does not demands any additional chemical functionalization and reactants requirements for drug detection.

Cocaine detection at trace levels as low as $10 \mathrm{ng} / \mathrm{ml}$ was reported using gold nanorods synthesized using seed-mediated, surfactant assisted method (D'Elia et al. 2018). Silver doped sol-gel SERS substrates were used to detect 5-fluorouracil, chemotherapeutic drug spiked in saliva at physiological
Fig. 5 Vibrational energy level diagram of a molecular system with Raman scattering process and infrared absorption

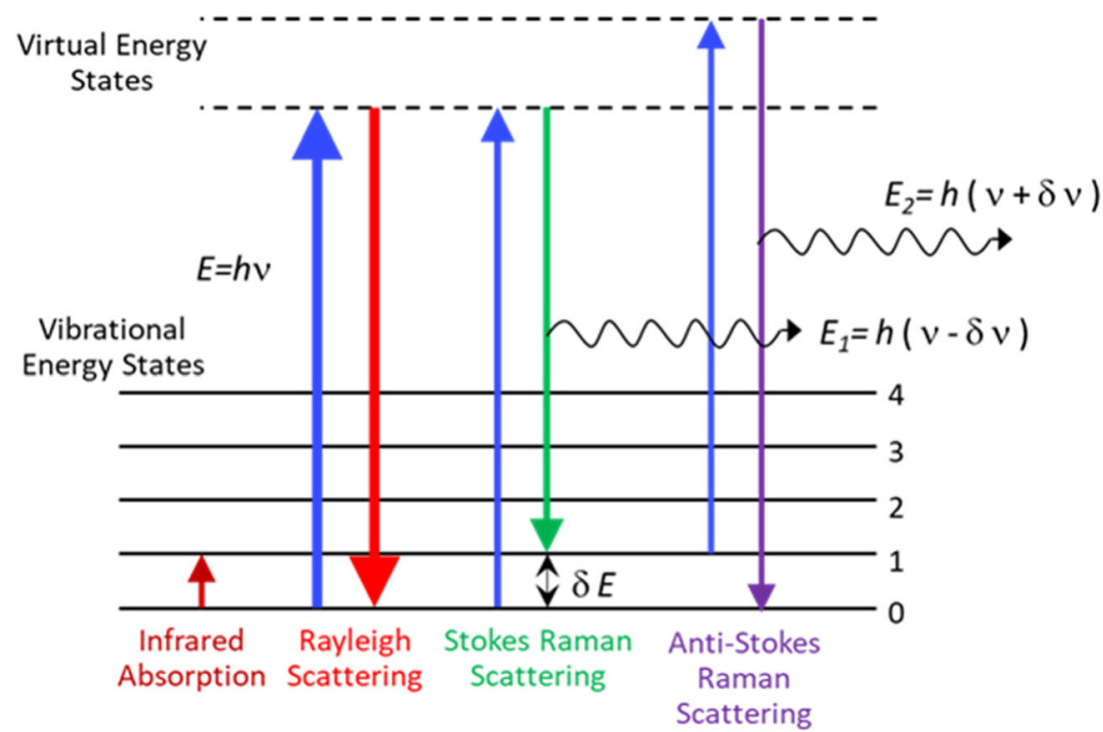




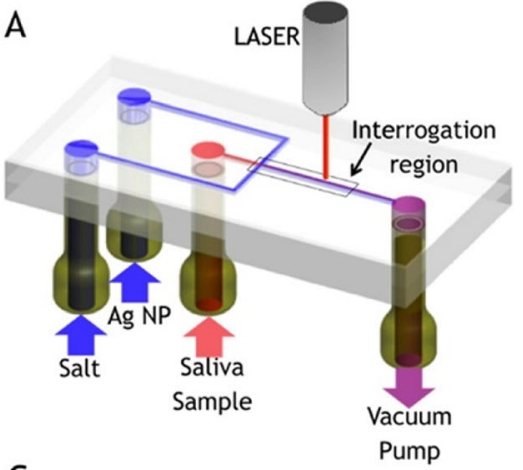

C

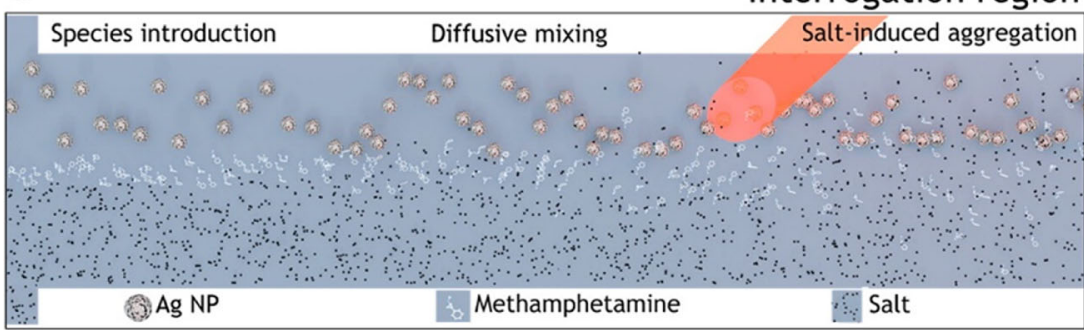

B

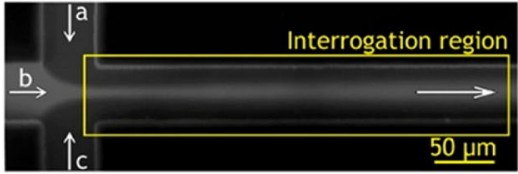

a: Ag NP

b: Sample

c: Salt
Fig. 6 Flow-focusing microfluidic device used for controlled Ag-NP aggregation. (A) Ag-NP suspension, a saliva sample, and salt solution are loaded in the device and driven through it by a vacuum pump. (B) At the flow-focusing junction, the sample stream is enveloped by the sidestreams and diffusion drives lateral mass transport between the laminar flows, here visualized with a fluorescent dye. (C) Schematic of the reaction: Ag NP, analyte and salt solution are introduced to the channel from

range of concentrations (Farquharson et al. 2005). The same group have extended similar studies on 5-fluorouridine and 5fluoro-2'-deoxyuridine too (Farquharson et al. 2008). Silver nano flowers formed on a paper substrate was successfully employed for SERS as well as ambient pressure mass spectrometry analysis aimed at the detection of Ketoprofen in dried saliva (Díaz-Liñán et al. 2020).

In another work, microfluidic SERS platform, created using homogeneous plasmonic mirror like capsules, has been utilized for the detection of the illicit drug, methamphetamine (MA) in urine and human saliva ( $\mathrm{Su}$ et al. 2019). Su et al. could identify the specific vibrational fingerprint band at 993 $\mathrm{cm}^{-1}$ in all the samples containing MA in ppm concentration, which was not observed in blank saliva. Detection of the primary component of marijuana, tetrahydrocannabinol (THC) in body fluids plays a critical role in forensic analysis and public health. Trace level detection of THC from saliva was reported using hybrid plasmonic biosilica nanomaterials by depositing silver nanoparticles (Ag NPs) into diatom photonic, where the band at $1621 \mathrm{~cm}^{-1}$ due to the $\mathrm{O}-\mathrm{C}=\mathrm{O}$ stretching in THC, could be observed (Sivashanmugan et al. 2019a, b). The group have extended the study and developed diatomaceous SERS substrates based protocol and detected THC using a portable device (Sivashanmugan et al. 2019a, b). Optoplasmonic materials are of high interest in SERS substrate fabrication due to their unique properties of comprising the left and flow toward the right. Analyte molecules resident in the focused stream diffuse laterally into the side flows. Salt ions also diffuse into the colloid stream inducing controlled nanoparticle aggregation, creating SERS-active clusters that convect downstream. Interrogating the region rich in colloid dimers, which provide intense plasmonic enhancement, we are able to achieve optimal SERS-based detection. Reprinted from (Andreou et al. 2013) Copyright (2013) American Chemical Society

both photonic and plasmonic elements. A layer of analytecarrying dielectric nano/micro spheres is placed on top of a monolayer of gold nanoparticles to enhance the intensity of the electric (E-) field localization and to enrich the analyte close to the electromagnetic hot spots. Surface receptors immobilized on these dielectric microsphere enable the binding of target analytes in liquid samples. Deposition of the analyte loaded microspheres on the self-assembled gold nanoparticle ensures a high local concentration of analytes in the electromagnetic "hot" surface. Optoplasmonic SERS substrates have been found effective in the detection of methamphetamine in saliva and urine at nanomolar concentrations (Hong et al. 2020). Li et al. have developed an immunochromatographic assay (ICA) based on SERS technique for detecting morphine, which is the main metabolic end product of opium and heroin. The detection limit of $2.4 \times$ $10^{-4} \mathrm{ng} / \mathrm{ml}$ has been obtained for opium by this method, which is significantly lower than traditional ICA method ( $\mathrm{Li}$ et al. 2020). Authors have proposed this method as a rapid morphine detection technique for the screening.

SERS technique of saliva has a high potential in clinical applications also. Lung cancer diagnosis from saliva was reported with SERS, using silver hydrosols. PCA-LDA analyses of the SERS spectra were able to discriminate lung cancer group from the control, where the major contributions were found to be due to the decrease in proteins and nucleic acid for 
cancerous patients (Li et al. 2011). SERS study was reported for the first time on saliva from patients with Sjögren's Syndrome (SjS) and validated with two-dimensional shear wave elastography data obtained from parotid glands. Combination of SERS spectral results with elastography studies have provided the sensitivity and specificity of $80 \%$ and $81 \%$ respectively (Moisoiu et al. 2020). SERS technique was also employed as a non-invasive tool for the diagnosis of oral cancer from saliva. Thiocyanate, which is regarded as biomarker for human health and smoking status of individuals, has been detected in saliva from the SERS spectra. The band at $2126 \mathrm{~cm}^{-1}$ from C-N stretch of thiocyanate has been found higher in cancer subjects (Fălămaș et al. 2020). Similar results have been obtained in study on oral dysplasia samples also (Daniel et al. 2020). SERS technique has been proposed for oral cancer diagnosis by evaluating the $\mathrm{S} 100$ calcium-binding protein P (S100P) present in saliva (Han et al. 2019). The results indicated a threefold increase of S100P in oral cancer patients as compared to healthy subjects Qiu et al. detected biochemical differences in the saliva of subjects with nasopharyngeal carcinoma when compared with healthy subjects with a diagnostic sensitivity of $86.7 \%$, specificity of $81.3 \%$ and accuracy of $83.9 \%$ (Qiu et al. 2016). Sialic acid (SA) determination in saliva can provide clues towards early diagnosis of breast cancer. Colloidal solution of citrate reduced silver nanoparticles as SERS substrates mixed with saliva collected from breast cancer patients have displayed a SA concentration of $18.5 \pm 9.7 \mathrm{mg} / \mathrm{dL}$ which is significantly higher compared to the $3.5 \pm 1.0 \mathrm{mg} / \mathrm{dL}$ in controls (Hernández-Arteaga et al. 2017). Hernández-Cedillo et al. used SERS method for the Sialic acid (SA) level determination in a study performed on 93 subjects which comprised of three classes, control, subjects with periodontitis and gingivitis (Hernández-Cedillo et al. 2019). The study found elevated levels of SA in periodontitis subjects in citrate reduced silver nanoparticles mixed with saliva. Monitoring of urease activity in saliva can be useful for the screening of helicobacter pylori infection and to prevent dental caries (Zhang et al. 2017). It is well-known that urea gets converted to $\mathrm{NH}_{3}$ and $\mathrm{CO}_{2}$ in the presence of urease. SERS peak due to urea present at $1003 \mathrm{~cm}^{-1}$ can be used to detect the presence of urease in oral cavity fluid. An intensity decline in this band was observed in saliva spiked with urease (Hu et al. 2019). Zamora-Mendoza et al. have carried out SERS-based non-invasive diagnosis of asthma by identifying biomarkers in saliva. Multivariate analysis of the spectral data has shown a sensitivity of $85 \%$, specificity of $82 \%$ and an accuracy of $84 \%$ for asthma diagnosis in children. The band at $1326 \mathrm{~cm}^{-1}$ from interleukin 8 (IL-8) has shown statistically significant differences between asthma patients and control group in addition to the increase in characteristic bands of lipids in asthma subjects (Zamora-Mendoza et al. 2019). Cao et al. have showed that SERS may be a possible tool for the detection of acute myocardial infarction (AMI) from saliva
(Cao et al. 2015). PCA-LDA analysis performed on the spectral data acquired from the saliva of normal and AMI patients have a diagnostic sensitivity and specificity of $80.4 \%$ and $81.4 \%$, respectively.

In a recent study, Žukovskaja et al. have demonstrated Pyocyanin metabolite detection in saliva using SERS based microfluidic biosensor at a detection limit of $10 \mu \mathrm{M}$. Pyocyanin is a metabolite specific for the pathogen Pseudomonas aeruginosa, which is the etiological agent for respiratory tract infections (Žukovskaja et al. 2017). Eom et al. have reported the utility of SERS technique for the detection of oseltamivir-resistant $\mathrm{pH} 1 \mathrm{~N} 1 / \mathrm{H} 275 \mathrm{Y}$ mutant virus in saliva (Eom et al. 2019). Oseltamivirhexylthiol (OHT), viral receptor functionalized on gold nanoparticles has been able to detect mutant viral at 1 PFU concentration. Sun et al. have developed a magnetic SERS immunesensor for detecting avian influenza virus (AIV) from saliva using a portable device (Sun et al. 2017). SERS combined with machine learning algorithms has been reported for the determination of nonstructural protein (NS1) present in saliva, which can be critical in early diagnosis of dengue fever (Othman et al. 2019). Wasik et al. detected the presence of the non-structural protein (NS1) in the adulterated artificial human saliva over the range of clinically relevant concentrations using SERS technique as an early detection procedure for dengue fever (Wasik et al. 2018). In a very recent work, SERS technique was suggested for the detection of SARS-Cov-2 from saliva in a preliminary study. Spectral differences have been identified in the gold nanoparticles mixed saliva spiked with $\mathrm{S}$ protein (Jinglin et al. 2020). Viral detection from saliva has been proposed in a recent study, where they were able to extract Raman signatures attributed to viral RNA (Desai et al. 2020). The group of Yacaman, who had previously developed the saliva-based SERS technique for breast cancer detection has come out with a new test for SARS-COV-2, by the SERS technique (Hernández-Arteaga et al. 2017; Yacaman et al. 2020).

\section{IR spectroscopy of saliva}

The mid-IR $\left(4000-400 \mathrm{~cm}^{-1}\right)$ region is the region of main interest for biomedical applications. This comprises of the so-called fingerprint region, exhibiting characteristic absorption peaks for lipids, proteins, amide I/II, carbohydrates, and nucleic acids (Balan et al. 2019; Su and Lee 2020). Similar to Raman spectroscopy, Infrared spectroscopy provides "whole biochemical fingerprinting" of samples by means of the spectral features. IR spectroscopy can be performed using either the traditional, "direct transmission" mode or the surface sensitive ATR- (Attenuated Total Reflection) mode. Bio-medical studies mostly involve samples in the condensed phase (solids and liquids) and the individual absorption bands have halfwidths $5-10 \mathrm{~cm}^{-1}$ at room temperatures. This allows the use 
of even miniature, portable Fourier transform (FT) and/or dispersive spectrometers for spectral measurements (Ayerden et al. 2014; Kruzelecky et al. 2017; Chai et al. 2020). FTIR gives highly accurate spectral data and have high sensitivity because of the multiplexing effect of total signal detection at any time, rather than single wavelength measurements as in diffraction spectrometers. The high accuracy of FTIR provides, precise frequency data, allowing very accurate spectral data processing like spectral subtraction and curve fitting can give information which can discriminate between even closely similar spectra of related species. Hence, FTIR spectroscopy is a very effective tool for bio-medical applications.

Takamura et al. have reported the ATR-FTIR spectra of five body fluids- peripheral blood, saliva, semen, urine and sweat (Takamura et al. 2018). The study coupled with chemometric analysis has been able to discriminate the body fluid types from the spectra, which is useful for forensic applications. Saliva spectra has shown characteristic peaks arising from proteins at $3279 \mathrm{~cm}^{-1}$ (Amide A), $1640 \mathrm{~cm}^{-1}$ (Amide I), $1537 \mathrm{~cm}^{-1}$ (Amide II) and $1239 \mathrm{~cm}^{-1}$ (Amide III). The symmetric and asymmetric $\mathrm{C}-\mathrm{H}$ stretching and carbonyl $(\mathrm{C}=\mathrm{O})$ stretch of ester groups contributed to peaks at $2943 \mathrm{~cm}^{-1}, 2854 \mathrm{~cm}^{-1}$, and $1743 \mathrm{~cm}^{-1}$. In addition, the thiocyanate characteristic band has been identified at 2057 $\mathrm{cm}^{-1}$. Quinn et al. have also used ATR-FTIR spectra for the discrimination of body fluids, for forensic applications (Quinn and Elkins 2017).

In a recent study, ATR-FTIR characterization of saliva has been found helpful in the diagnosis of chronic kidney disease (CKD). It has been found that the spectral markers of thiocyanate and phospholipids/carbohydrates can be a valuable biomarker panel for identifying CKD (Rodrigues et al. 2019a, b). Amide II band present at $1545 \mathrm{~cm}^{-1}$ in the ATR-FTIR spectra of saliva has been reported to be a characteristic marker for Psoriatic and Diabetic patients (Bottoni et al. 2015). A recent work has explored this technique in the diagnosis of periodontitis from saliva (Beyer-Hans et al. 2020). PCA analysis performed on ATR spectra could differentiate between controls and generalized aggressive periodontitis patients. Other studies have been reported on the differentiation of aggressive and chronic periodontitis using ATR-FTIR spectroscopy. These studies have identified differentiating features in 2800-3000 $\mathrm{cm}^{-1}$ assigned to lipids and proteins in periodontitis patients (Derruau et al. 2019). ATR-FTIR spectroscopic investigation of saliva has also been exploited to monitor the physiological stress in human body (Khaustova et al. 2010; Caetano Júnior et al. 2016). Ferreira et al. have recently shown the possibility of using IR spectra of saliva for non-invasive breast cancer detection. The authors have suggested two characteristic bands, 1041 $\mathrm{cm}^{-1}$ in the second-derivative spectra and the 1433-1302.9 $\mathrm{cm}^{-1}$ region of the original spectra for effective identification of benign and cancerous subjects from control (Ferreira et al. 2020). ATR spectroscopy has been employed for monitoring the biochemical variations in saliva collected from salivary gland tumour patients (Fig. 7) (Paluszkiewicz et al. 2020). Increase in phosphate-associated band at $\sim 1074 \mathrm{~cm}^{-1}$ has been found during tumour progression in these subjects. In addition, an increase in $\beta$-sheet band at $1543 \mathrm{~cm}^{-1}$ and decrease in $\alpha$ helix peak frequency around $1634-1640 \mathrm{~cm}^{-1}$ region has also been observed for the tumour samples. Clear alterations in secondary structure of proteins were evident in the saliva of tumour samples (Paluszkiewicz et al. 2020). Progesterone level variations during each trimester of pregnancy in normal and diabetic women have been observed in the saliva samples of corresponding subjects (Sultana et al. 2011).

Rodrigues et al. studied FTIR spectral patterns of saliva collected from females suffering from burning mouth syndrome (BMS), and enhancement of nucleic acid and thiocyanate bands has been found in these with respect to healthy females (Rodrigues et al. 2019a, b). Thiocyanate increase has been attributed due to greater proliferation of microorganisms in the saliva. Chances of cell necrosis have been speculated from the increase in DNA bands in the infrared spectra of saliva from chronic smokers (Rodrigues et al. 2017). Collagen content increase has also been found comparatively high in saliva of former smokers than chronic smokers, which indicated the improvement in inflammation tissue regeneration capacity after quitting smoking. FTIR spectroscopy of saliva has been used for the early detection of neonatal sepsis, which has been one of the primary cause for global neonatal mortality (Yunanto et al. 2019). Changes in DNA and protein composition have been evident from the spectra, which suggested protein damage in neonates struggling from sepsis infection. Recent years have witnessed high research interest in exosomes generated in urine, blood, and saliva, for clinical applications (Krafft et al. 2017, Mihály et al. 2017, Kim et al. 2018, Chiang and Chen 2019, Kim et al. 2019a, b, Yap et al. 2019). Salivary exosomes collected from oral cancer patients and healthy subjects have been evaluated in a recent work, where PCA-LDA (principal component analysis-linear discriminant analysis) could effectively discriminate them with a sensitivity, specificity and accuracy of $100 \%, 89 \%$, and $95 \%$, respectively (Zlotogorski-Hurvitz et al. 2019). In addition to the clinical diagnostics applications, IR spectroscopy has also been used for detecting drug abuse from IR spectra of human saliva. Hans et al. carried out ATR-FTIR investigation of saliva to obtain spectral features of cocaine at around $1280 \mathrm{~cm}^{-1}$ and between 1760 and $1710 \mathrm{~cm}^{-1}$ with an LOD of $\sim 10 \mu \mathrm{g} / \mathrm{ml}$ (Hans et al. 2012). An extended study reported by the same group has obtained a lower limit of $\sim 1 \mu \mathrm{g} / \mathrm{ml}$ (Hans et al. 2014).

\section{Other methods}

In addition to plasmonics and vibrational spectroscopic techniques, other approaches including or combined with optical 
Fig. 7 Curve-fitting analysis of the $900-1200 \mathrm{~cm}-1$ spectral interval (a - control group, $\mathrm{b}-\mathrm{TM}$ patients) and amide I/II with second derivative spectra (c - control group, d-TM patients) profiles together with (e) averaged ATRFTIR spectra of saliva samples (black line - control group, red line-TM patients). Spectra were averaged from five healthy volunteers and five salivary gland tumour patients spectra, respectively. Reprinted from

(Paluszkiewicz et al. 2020) (a) $900-1200 \mathrm{~cm}^{-1}$ : control

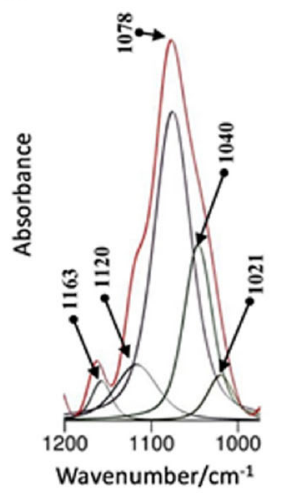

(b) $900-1200 \mathrm{~cm}^{-1}: \mathrm{TM}$

(c) amide I and II - control

(d) amide I and II - TM

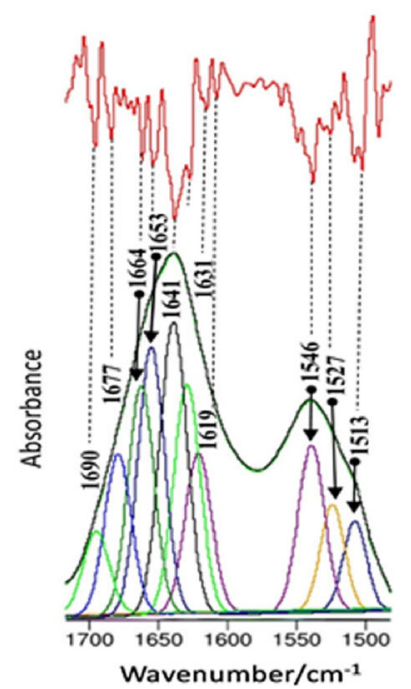

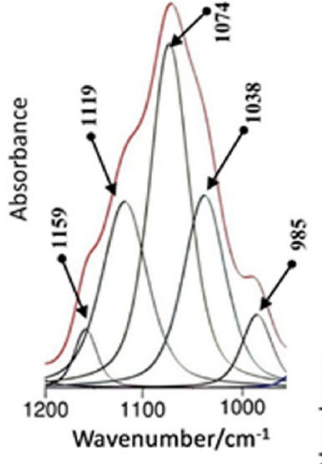

Wavenumber $/ \mathrm{cm}^{-1}$

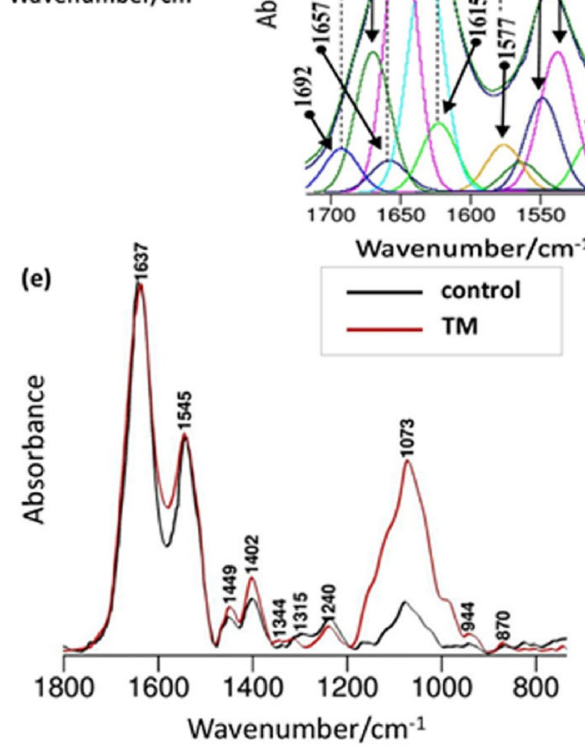

spectroscopy have also been used for saliva based research. Intense ultrashort infrared laser light propagation through matter can cause supercontinuum white light generation, in which transmitted light spectra cover a much broader spectral range, compared to incident light. Our group have earlier conducted ultrafast supercontinuum generation studies in water using a femtosecond Ti-sapphire laser $(820-\mathrm{nm}$ and duration $<45 \mathrm{fs})$ in presence of salivary proteins (Chidangil et al. 2007). It has been observed that the addition of salivary protein $\alpha$-amylase resulted in suppressing the supercontinuum generation in (a)

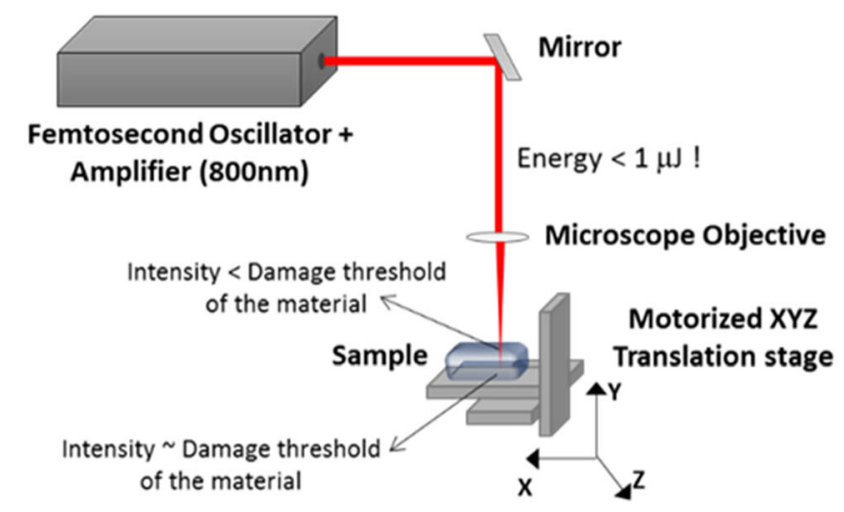

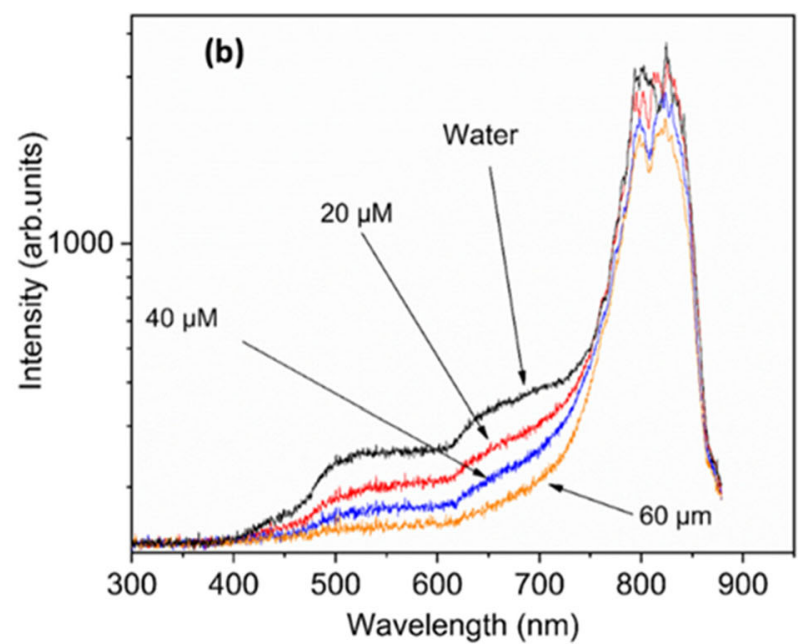

Fig. 8 (a) Schematic of the experimental set up and (b) White light spectrum of pure $\mathrm{H}_{2} \mathrm{O}$ and $\mathrm{H}_{2} \mathrm{O}+\alpha$-amylase samples. Reproduced from (Chidangil et al. 2007) under Creative Commons (CC BY 4.0) 
water, as shown in Fig. 8. Electron scavenging property of proteins has been identified as the rationale for this suppression. The experiments conducted on other proteins such as immunoglobulin, lysine, and arginine didn't cause any suppression, which indicates the potential of this technique for sensing the stress marker $\alpha$-amylase in saliva.

In a recent work, a label-free microfluidic-optoelectronic sensing platform for Point-Of-Care (POC) detection of stress biomarkers (cortisol, serotonin, dopamine, norepinephrine, and neuropeptide) in human body fluids, including saliva, has been developed. The study relies on the absorption characteristics of these biomarkers which lies in the near ultraviolet region of electromagnetic spectra (Ray and Steckl 2019). Yuvaraj et al. have conducted fluorescence-based investigation of saliva for oral cancer detection (Yuvaraj et al. 2014). The study targeted the auto fluorescence from salivary porphyrin excited at $405 \mathrm{~nm}$, which has shown increase in its emission characteristics at 627 and $687 \mathrm{~nm}$ with respect to normal cases. In addition, the presence of flavins emission has been also observed as a small hump at $510 \mathrm{~nm}$ in malignant saliva. A fluorescence biosensor for ultrasensitive detection of oral cancer biomarker, Interleukin-8 (IL-8) protein in saliva has been also reported (Tan et al. 2008). Pradhan et al. have utilized stokes shift spectroscopy as a potential technique for the detection of oral malignancy from saliva (Kumar et al. 2018). Farago et al. have recently developed a fibre optic fluorescence sensor for the detection of blood in saliva (Farago et al. 2019). Coumarin based Fluorescent probes have been used for the detection of hydrogen sulphide in human saliva (Zaorska et al. 2018).

At present, markers for many diseases, like various cancers, are mostly detected by immunochemical methods like "ELISA" and Radio Immuno Assay. These techniques are time consuming, require prior knowledge of which antigen/ antibody you are looking for, and so can be used only for specific proteins. High performance liquid chromatographylaser induced fluorescence (HPLC-LIF) technique has been used for ultrasensitive protein profiling of clinical samples like body fluids (blood, saliva, vaginal wash), tissue homogenates, and cellular lysates, for screening and early detection of oral, cervical, breast and ovarian cancer (Patil et al. 2013; Patil et al. 2015). Protein profiles recorded from the saliva of normal, premalignant and malignant oral cancer patients (Fig. 9) were analysed with statistical pattern analysis methods like PCA, and discrimination of normal, pre-malignant and malignant conditions has been achieved with high specificity and sensitivity (Patil et al. 2015). The protein profiling by HPLC-LIF has many advantages like very high sensitivity (subfemtomole levels), no need of prior knowledge of the identity of the marker proteins for a given disease condition, and relatively fast, few tens of minutes.

Mass spectrometry coupled with HPLC also has been used for the identification of salivary biomarkers for clinical
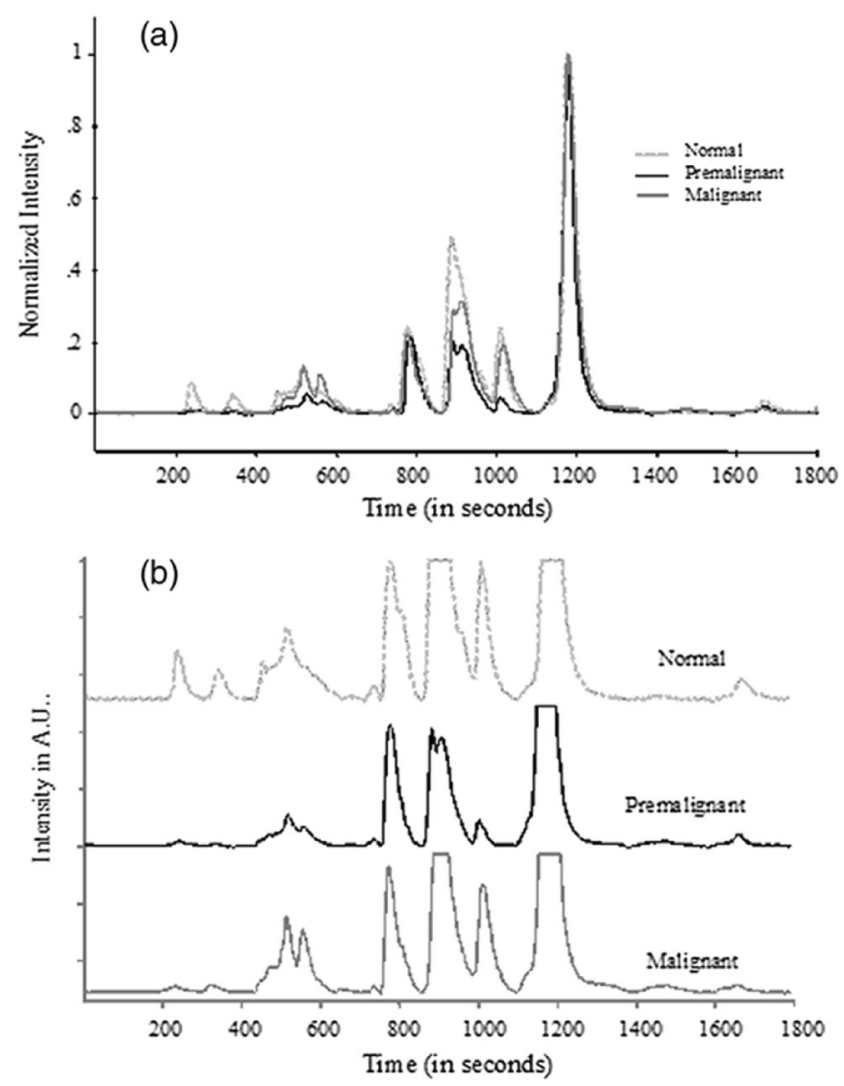

Fig. 9 (a) Typical pre-processed saliva chromatograms of normal, premalignant, and malignant classes (normalized with respect to $1200 \mathrm{~s}$ peak). (b) Expanded (five times) chromatograms in (a). Reprinted from (Patil et al. 2013)

diagnosis (Bigler et al. 2009). Laser induced breakdown spectroscopic study on saliva from smokers has witnessed an elevated calcium concentration, due to demineralisation (solubility) process which is related to the dissolution of $\mathrm{Ca}$ element in tooth lattice into saliva (Zahroh et al. 2019). A.K. Singh et al. have recently reported a handheld optical device which can be used for self-monitoring of glucose level in saliva (Singh and Jha 2019). The enzyme glucose oxidase functionalized on the sensing strip along with a $\mathrm{pH}$ sensitive dye produces an enzymatic reaction followed by $\mathrm{pH}$ change upon glucose addition, which will be detected. A portable fluorescence based sensor has been developed for the detection of lithium in saliva excited at $590 \mathrm{~nm}$ wavelength, in which the emission at $620 \mathrm{~nm}$ due to quinizarin-lithum ions interaction is monitored. The device has demonstrated a linear

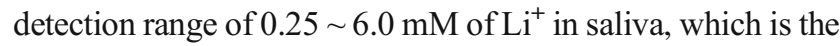
range of interest for therapeutic applications (Kim et al. 2011). Endo et al. has reported reflectometry based detection of influenza virus in saliva. Detection of influenza from saliva was carried out by evaluating the reflectance changes with respect to viral concentrations using antibody immobilized on a nanoimprint lithography based two dimensional photonic crystal biosensor (Fig. 10) (Endo et al. 2010). 

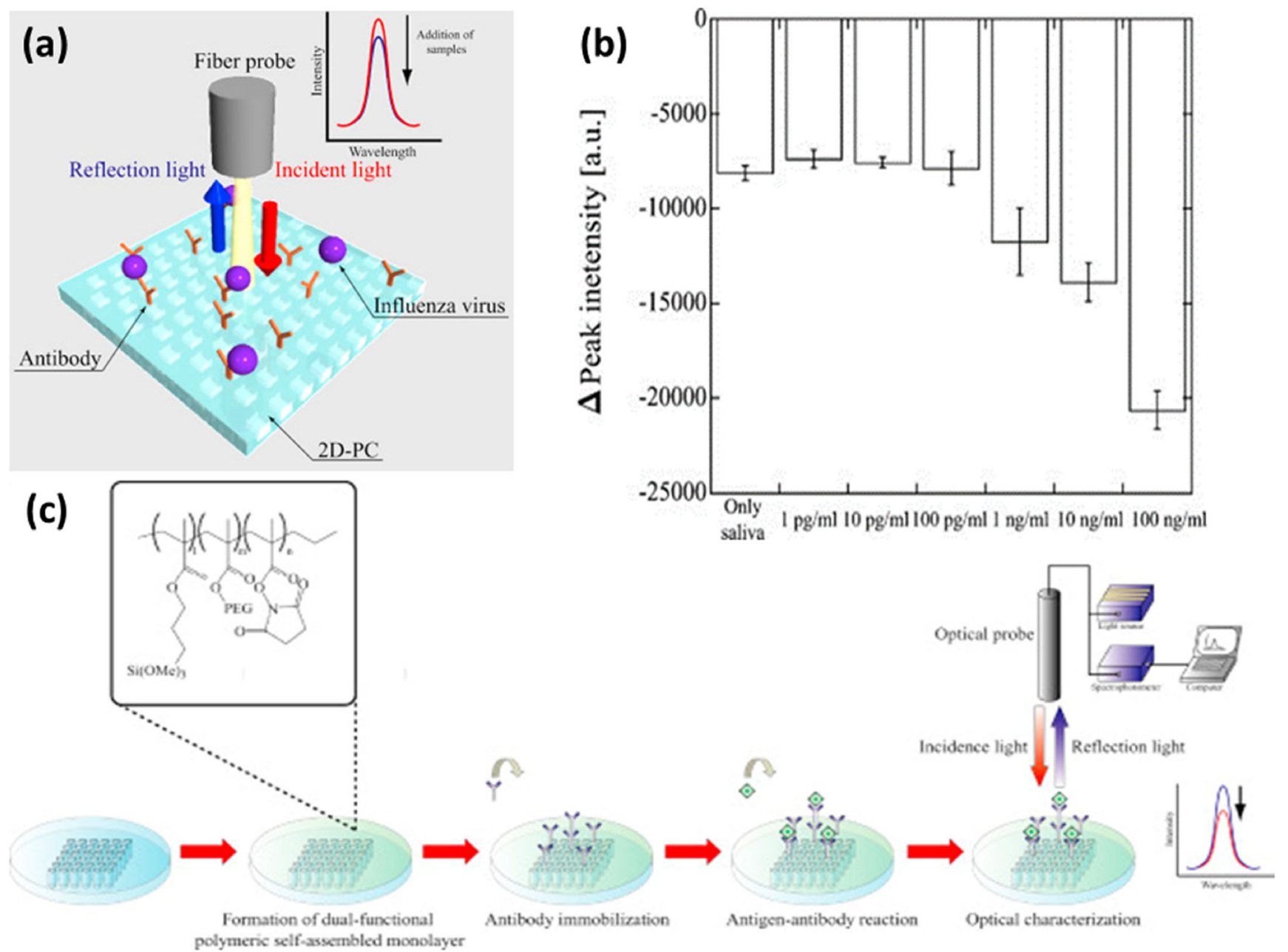

Fig. 10 (a) Schematic illustration of reflectometric detection principle for influenza virus in human saliva using nanoimprint lithography (NIL)based two-dimensional (2D) photonic crystal (PC). (b) Experimental

Convat, a research team based at the Catalan Institute of Nanoscience and Nanotechnology, Spain, has recently announced a laser based nano-interferometric biosensor, which is claimed to be useful for real time and highly specific early diagnosis of COVID-19 from saliva. The sensor relies on the refractive index variation due to attachment of viral molecules on bioreceptors immobilized on sensor surface, which alter the direction in which light propagates. The distortion in this propagation direction is monitored for rapid viral diagnosis (Wallace 2020). In a recent work, J. Wang et al. have developed dual-functional plasmonic biosensors which comprise the plasmonic photothermal (PPT) effect and localized surface plasmon resonance (LSPR) sensing transduction for the detection of the selected sequence from SARS-CoV-2 (Qiu et al. 2020). Two dimensional gold nanoislands (AuNIs) functionalized with complementary DNA receptors were employed for the detection of SARSCoV-2 through nucleic acid hybridization. The thermoplasmonic heating generated by the gold nanoislands procedure for the reflectometric detection of influenza virus in human saliva using antibody-immobilized 2D-PC. Reprinted from (Endo et al. 2010)

chip via illumination at plasmonic resonance frequency found to elevate the in-situ hybridization temperature and facilitate the accurate discrimination of two similar gene sequences. The limit of the detection of the dualfunctional LSPR sensors for the selected SARS-CoV-2 was estimated to be $0.22 \mathrm{pM}$. The developed technique to provide real-time, label-free detection of viral sequences, including RdRp-COVID, ORF lab-COVID, and E-genes from SARS-CoV-2, can be probably extended for viral detection from saliva (Qiu et al. 2020).

\section{Saliva: a clinical sample for COVID-19}

Saliva is regarded as one of the primary transmission routes for COVID-19 due to its high predilection for spreading via sneezing coughing, breathing, and even through conversations (Fig. 11). In view of these, World Health Organization has urged the public to maintain $\sim 1$ $\mathrm{m}$ distancing from each other as a preventive measure to 
minimize COVID-19 transmission. This has been further revised to $2 \mathrm{~m}$ as per the guidelines issued by Centre for Disease control and prevention (CDC) (Bourouiba 2020). Viral detection based on saliva samples has been already employed efficiently for Zika and Ebola viruses (Niedrig et al. 2018; Khurshid et al. 2019). Viral RNA presence has been detected in the saliva of Zika infected subjects even after 29 days of symptom onset (Barzon et al. 2016). RT-PCR test results conducted on COVID-19 suspected patient's samples have detected viral RNA presence up to the $10^{8}$ copies $/ \mathrm{mL}$ (Wang et al. 2004). Moreover, studies have also observed viral presence in saliva samples of patients which were found negative in nasopharyngeal aspirates (To et al. 2017). As per a recent study, viral presence has been detectable in the saliva of more than $90 \%$ patients suffering from SARS-CoV-2 infection (To et al. 2020a, b).

Reliability of saliva samples for COVID-19 diagnostics has been evaluated in a recent study, where PCR results of saliva were found positive for all the clinically diagnosed COVID19 patients. The study also showed the viral presence in two subjects, even after the "gold standard" swab results turned out to be negative (Azzi et al. 2020). A study performed on SARS-COV-2 infected ferrets have also reported the appearance of viral RNA in the saliva, in addition to its presence in urine and feces (Kim et al. 2020). The amount of viral load in saliva has been at its maximum during the first week after symptom onset in SARS-COV-2 (To et al. 2020a, b). Epithelial cells present in the salivary glands have been recognized as the initial targets for SARS-COV-2, which might be the probable cause for the high viral load in saliva even at the early stages of infection (Liu et al. 2011). High expression of host cell receptors has been identified in the epithelial cells of oral mucosa (Xu et al. 2020a). The immunofluorescence staining study by Srinivasan et al. have demonstrated the expression of ACE2 in the epithelial cells of the oral mucosa (Srinivasan et al. 2020). The exfoliated epithelial cells in saliva have been also found with high expression of ACE2 receptor. A study reported on the previous SARS-COV epidemic patients has witnessed viral RNA upto $\sim 6.38 \times 10^{8}$ copies $/ \mathrm{ml}$ in saliva, which was higher than that obtained from throat wash (Wang et al. 2004). The similarities and differences of saliva, between SARS-CoV and 2019-nCoV, are compared in a recent article, in terms of diagnosis value of saliva, direct invasion to oral tissues, and saliva droplet transmission, possibly explaining the faster transmission speed of 2019-nCoV (Xu et al. 2020b). The studies mentioned here clearly demonstrate that saliva can be a preferable diagnosis route for early detection of COVID-19 (Chojnowska et al. 2018; Xu et al. 2020c). Recently, US FDA has also given approval for accelerated emergency use of a saliva-based diagnostic kit for SARS-COV-2 (FDA 2020).

\section{Summary and future prospects}

Despite all these advantages, the usefulness of saliva for routine clinical testing is not yet fully recognized. Even though, photonics technologies have found ubiquitous applications in diverse scientific fields, the clinicians and biomedical



Fig. 11 Potential diagnostic value of saliva and transmission of 2019$\mathrm{nCoV}$. Possibly binding to host-cell receptor of ACE2 expressed in salivary glands and tongue, 2019-nCoV is detected in saliva. Combined with infectious fluids from respiratory system, 2019-nCoV via large saliva droplets sets up short-distance transmission and hardly form longdistance aerosol transmission outdoors due to complicated physical and biological decay. Prevention of droplets formation, implementation of air disinfection, and blockage of droplets acquisition could possibly slow down 2019-nCoV dissemination (Reprinted from (Xu et al. 2020c) Under Creative Common License (http://creativecommons.org/licenses/ by $/ 4.0 /$ ) 
fraternity are still not fully conversant about the potential of photonics tools that can be used for routine applications in clinics. As indicated above, several studies have already pointed out the utility of saliva as a pool of biomarkers for the noninvasive detection of caries, periodontal diseases, oral cancer, lung cancer, prostate cancer and diabetes. Tables 1, 2, 3, 4, 5 to 6 summarize the recent research in photonics/optical spectroscopy based studies on saliva as a body fluid for clinical and other general applications.

As is evident from Tables 1, 2, 3, 4, 5 to 6, saliva is a highly suitable body fluid for screening of not only clinical aspects but also in many other areas like problems in the use of dental accessories, influence of metallic elements in conditions like malnutrition, evaluation of effects of dangerous external invasions like exposure to nuclear radiation or chemical/biological agents. Amongst all biofluids, saliva is easiest to collect and the collection is non-invasive. As seen from the various studies discussed above, saliva shows numerous biomarkers, in many abnormal states in the living system. As of now, clinicians are completely relying on laboratory-based RT-PCR assays of saliva for diagnostic applications, especially in viral detection methods, even though false positives/negatives are a major issue in this technique. Photonics-based techniques can be of great interest in developing reliable technologies for the detection/identification of viruses like SARS-CoV-2. Use of saliva as the clinical specimen has several possibilities including detection of virions, identification of specific antibodies against Virus and identification of markers of the non-specific immune response in saliva. Saliva can be a reliable source for new disease biomarkers and/or understanding of pathways involved in diseases. Even though established techniques such as two dimensional (2D)-gel electrophoresis, matrix assisted laser desorption ionization (MALDI) and surface-enhanced laser desorption/ionization (SELDI)-mass spectroscopy, and capillary electrophoresis (CE) can acquire protein, or other markers' profiles from clinical samples, these suffer from several drawbacks. Two-dimensional polyacrylamide gel electrophoresis (2D-PAGE) is time consuming, require elaborate sample preparation and in addition to the presence of minor proteins at trace concentrations can be masked by major proteins. Surface-enhanced laser desorption/ionization (SELDI)Time of Flight (TOF) mass spectroscopy (MS) or other mass spectrometric methods require bulky instrumentation and qualified professionals for operation, making them unsuitable for large-number-screening at multiple locations in a short period, as will be required in pandemic situations.

Advanced research in salivaomics can play a pivotal role in screening and early detection of many diseases as well as disease-causing agents like virions and microbes (Farah et al. 2018; Liu et al. 2018; Shah 2018; Gug et al. 2019; Pathiyil and Udayasankar 2019). In spite of this possibility, acceptance of salivary markers for clinical applications, like regular screening and diagnosis, follow-up in therapy, or point-of-care/point of use applications, like screening and environmental monitoring in situations like the COVID pandemic, has not happened yet. The possible reason for this seems to be the fact that all such studies have been carried out by only one or two groups with specific sample classes, and has not been validated over large groups of cohorts to ensure adequate representation of sample/disease heterogeneity. What is urgently required to make salivaomics an effective diagnostic approach is a close collaboration between Academia with multi-disciplinary expertise-Medical, Physical and Engineering sciences-and Regulatory and Funding Agencies to standardize the technologies involved, through extended research by multiple groups in a concerted manner. Another essential requirement is that the markers observed in saliva, mainly proteins, enzymes and DNA/ RNA species should be studied further by bio-chemical and spectroscopic methods, including high-sensitivity mass spectrometry, from the point of view of correlating them to one another, to provide fundamental information about the different bio-molecular interactions, stages and variations in the disease, so that their validity as suitable markers can be further confirmed.

The lack of such a concerted approach has slowed the pace of standardization and routine use of saliva for clinical applications, leaving its potential for clinical applications unutilised. At present, photonics techniques has been in the forefront for providing solutions to medical community for early detection of diseases and prognosis of treatment. It may be appropriate to mention another major aspect of photonics technology highly relevant in the present context. Photonics systems operate through interaction of photons with matter, a physically non-contact process for the investigators. This allows the observations of materials by remote sensing, without the need for the observer to be in close proximity of the subject or material which is being studied. With current advances in lasers, spectrographs and imaging, and information technology, it is thus possible to use photonics-based portable instrumentation in applications needing observation of, subjects in intensive care units (ICUs), neonatal, differently abled and isolation/quarantine conditions or environmental samples from suitable distances. Finally, it has to be noted that current photonics systems enable observation of multi-modal (LIF+ RAMAN, LIF+ LIBS, Raman + LIBS, Absorption +Fluorescence) spectral observations on a same given sample in a single (e.g. resonance Raman and fluorescence, absorption and fluorescence) measurement, or one after the other without any change in the sample characteristics. Similarly, multi-wavelength spectral studies also can be done. Both these techniques can provide multiple data sets on a given sample, enabling more accurate data processing by machine-learning and artificial intelligence (AI) methods, so that specificities and sensitivities can be improved over the current 80-90\% level. Such instrumentation can carry out multi-modal spectral 


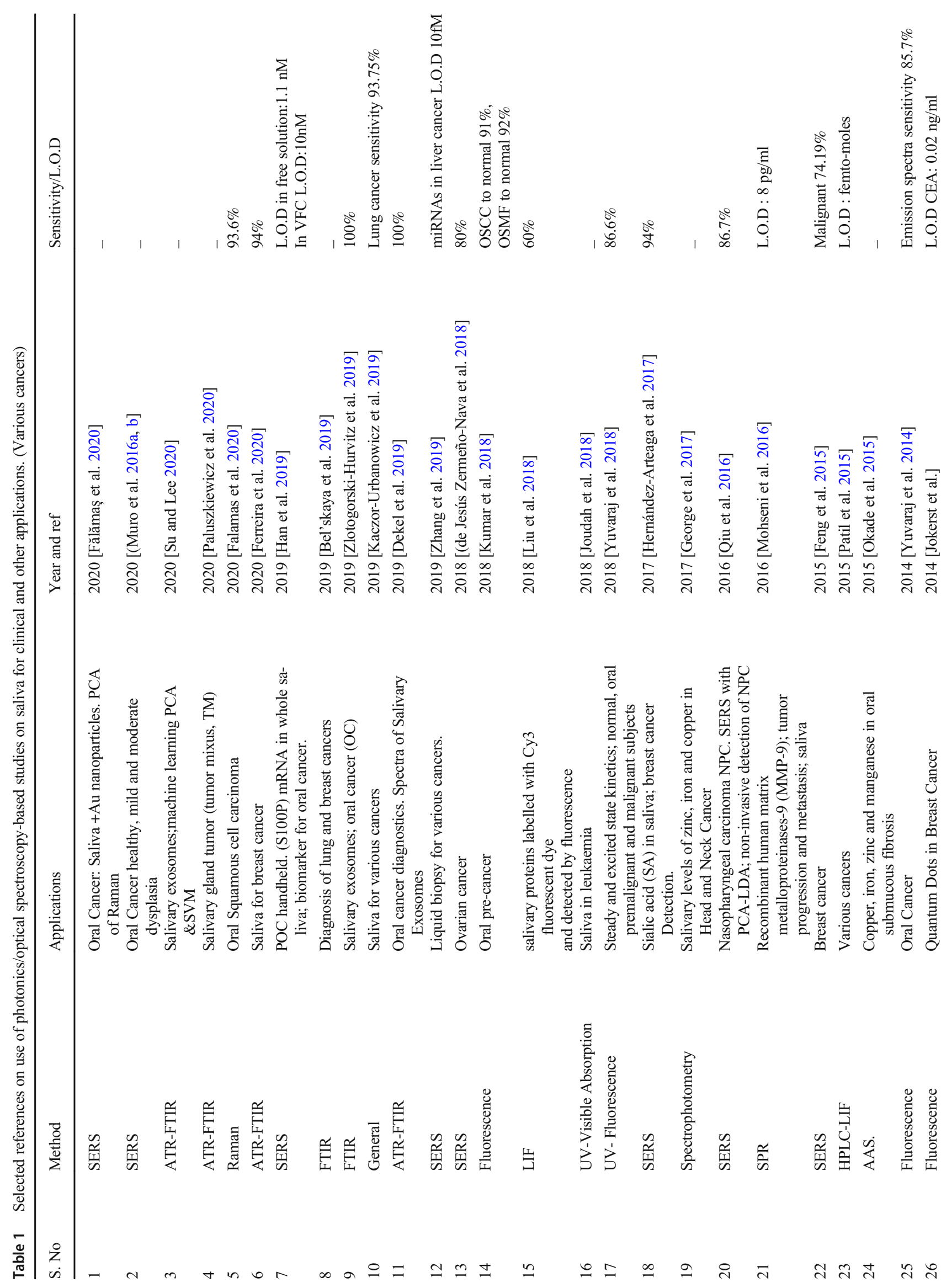




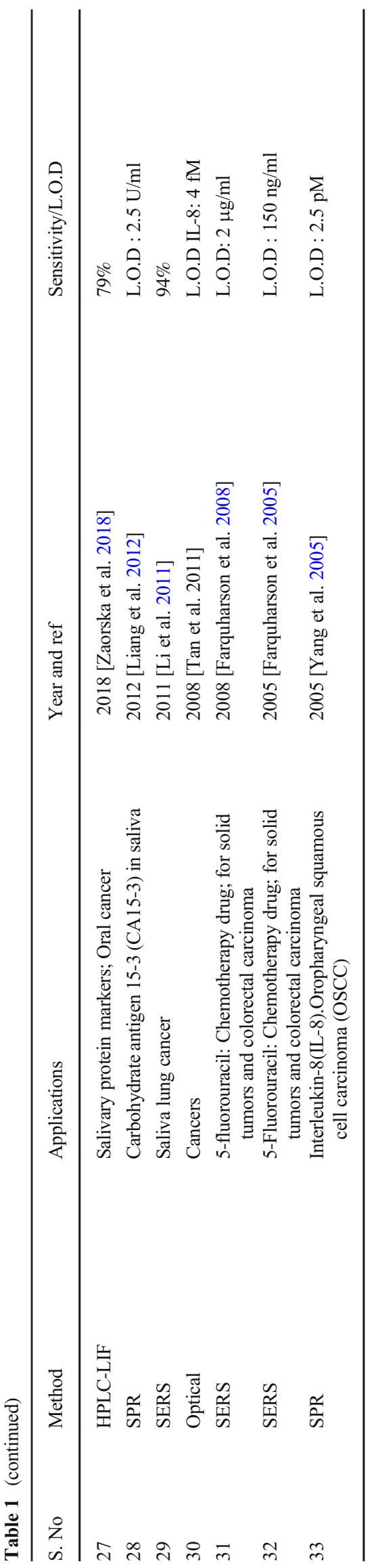

data acquisition, providing unambiguous identification and classification (Dhanada et al. 2020). This is especially of great advantage for clinical samples because all clinical samples, usually, are suitable for both fluorescence and Raman spectral studies, and current laser systems can give excitation wavelengths in the UV region. This allows a single laserspectrometer combination system which can simultaneously give fluorescence and Raman, without any mutual interference, since the fluorescence form many physiological samples usually comes well-after $300 \mathrm{~nm}$, while the Raman scattered radiation, which falls in the $100-3000 \mathrm{~cm}^{-1}$ region after the excitation wavelength comes before the fluorescence, so that the two spectra show no mutual interference (Lednev 2019).

It is seen that remote observation of multiple spectral information can be highly useful in present circumstances, when many people have to be tested for their health status, keeping social distances. It is possible to monitor the health status of an individual by looking at even exposable organ surfaces like skin, for such screenings in remote mode, since the laser powers for LIF are at safe levels for exposure. In future, one can thus expect considerable research in bio-medical applications with such advanced multi-modal, multi-excitation techniques, applicable in vivo with accessible organs (skin, oral cavity) and easily accessible samples like saliva and breath.

\section{Conclusion}

The present situation arising from the COVID pandemic has highlighted the need of universal screening technologies with fast, sensitive devices for in situ screening of large cohorts at multiple locations like airports or other areas where large numbers assemble for various purposes. Early diagnosis is also necessary in many situations in hospitals, clinics, test laboratories, and even at home. Portable/handheld screening devices comprising of Photonics tools coupled with machine learning and artificial intelligence, can be developed. Powerful optical techniques available at present have demonstrated the capabilities to detect, diagnose and stage different kinds of infections and non-infections disease with very high sensitivity and specificity with minimal sample handling. Such systems can be easily adapted for the diagnosis of COVID-19 kind of pandemic. The photonics of saliva offer an area of large possibilities for such applications. A major noteworthy factor in using the photonics-based methods is the possibility of the multi-modal approach. In almost all work so far, attempts have been concentrated on using only a single modality, like Raman, LSPR, LIF, and IR. The main consequence of such mono-modal approach has been results with specificities and sensitivities in the range of $80-90 \%$. But it is highly likely that a multi-modal approach, say, combination of two or three spectroscopic data sets with AI/Machine Learning (ML) techniques should be able to give still better 
Table 2 Selected references on use of photonics/optical spectroscopy-based studies on saliva for clinical and other applications. (Viral and other pathogen-related disorders)

\begin{tabular}{|c|c|c|c|c|}
\hline 1 & SERS & $\begin{array}{l}\text { Spike protein (S protein) of SARS-CoV-2 } \\
\text { in human saliva }\end{array}$ & 2020 [Jinglin et al. 2020] & - \\
\hline 2 & Fluorescence & Coronavirus diagnosis & 2020 [Bioptics World Editors 2020] & _ \\
\hline 3 & SERS, SPR & H1N1, HAdV and SARS-CoV-2 & 2020 [Cui and Zhou 2020] & $\begin{array}{l}\text { SERS: } 50 \text { and } 10 \text { pfu } \mathrm{mL}-1 \\
\text { SPR:0.22 pM }\end{array}$ \\
\hline 4 & Raman & Detection of RNA viruses in saliva. & 2020 [Desai et al. 2020] & $92.5 \%$ \\
\hline 5 & SERS & SARS-CoV-2 & 2020 [Yacaman et al. 2020] & _ \\
\hline 6 & SPR & $\begin{array}{l}\text { Immunosensors: viruses, microbes, } \\
\text { extracellular vesicles (EV) }\end{array}$ & 2020 [Choi et al. 2020] & - \\
\hline 7 & Interferometry & COVID- 19 saliva test & 2020 [Wallace 2020] & $\begin{array}{l}\text { L.O.D miRNA: attomole(am) range, } \\
4 \text { CFU/mL for whole } \\
\text { pathogen detection. }\end{array}$ \\
\hline 8 & SERS & $\begin{array}{l}\text { Pandemic H1N1 (pH1N1) virus } \\
\text { in human saliva. }\end{array}$ & 2019 [Eom et al. 2019] & L.O.D : 1 PFU \\
\hline 8 & SERS & $\begin{array}{l}\text { Immunoassays for Detection } \\
\text { of Botulinum Toxins }\end{array}$ & 2019 [Kim et al. 2019a, b] & $\begin{array}{l}5.7 \mathrm{ng} / \mathrm{ml} \text { (Type A L.O.D) } \\
1.3 \mathrm{ng} / \mathrm{ml}(\text { Type B L.O.D) }\end{array}$ \\
\hline 9 & SERS & Bacteria sensing & 2019 [Wang et al. 2019] & - \\
\hline 10 & SERS & Avian influenza virus- $\mathrm{H} 3 \mathrm{~N} 2$ & 2017 [Sun et al. 2017] & $10^{2} \mathrm{TCID}_{50} / \mathrm{mL}$ \\
\hline 11 & SERS & $\begin{array}{l}\text { Pyocyanin (PYO), biomarker } \\
\text { for Pseudomonas infections; in saliva. }\end{array}$ & 2017 [Žukovskaja et al. 2017] & L.O.D: $0.5 \mu \mathrm{M}$ \\
\hline 12 & SPR & Avian influenza virus H5N1. & 2012 [Bai et al. 2012 & L.O.D : $0.128 \mathrm{HAU}$ \\
\hline 13 & Reflectometry & Influenza virus & 2010 [Endo et al. 2010] & L.O.D: $1 \mathrm{ng} / \mathrm{ml}$ \\
\hline
\end{tabular}

Table 3 Selected references on use of photonics/optical spectroscopy-based studies on saliva for clinical and other applications. (Other disorders)

\begin{tabular}{|c|c|c|c|c|}
\hline 1 & SERS & Saliva. Sjögren's syndrome $(\mathrm{SjS})$ & 2020 [Moisoiu 2020] & $96.5 \%$ \\
\hline 2 & ATR-IR & Periodontal Diseases & 2020 [Beyer-Hans et al. 2020] & _ \\
\hline 3 & ATR-FTIR & $\begin{array}{l}\text { Bio fluids including saliva; Review, } \\
\text { clinical applications }\end{array}$ & 2020 [Naseer et al. 2020] & - \\
\hline 4 & Raman & $\begin{array}{l}\text { Amyotrophic Lateral Sclerosis (ALS) } \\
\text { diagnosis }\end{array}$ & 2020 [Carlomagno et al. 2020] & - \\
\hline 5 & SERS & Periodontitis, Sialic Acid (SA) & 2019 [Hernández-Cedillo et al. 2019] & $69.6 \%$ \\
\hline 6 & SERS & $\begin{array}{l}\text { To evaluate the activity of urease in saliva. } \\
\text { Dental caries; helicobacter pylori infection }\end{array}$ & 2019 [Hu et al. 2019] & L.O.D: $2.35 \mu \mathrm{g} / \mathrm{m}$ \\
\hline 7 & SERS & $\begin{array}{l}\text { biomarkers of bronchial inflammation } \\
\text { in the saliva of children with asthma }\end{array}$ & 2019 [Zamora-Mendoza et al. 2019] & $85 \%$ \\
\hline 8 & ATR-FTIR & Chronic kidney disease & 2019 [Rodrigues et al. 2019a, b] & $92.8 \%$ \\
\hline 9 & FTIR & Burning Mouth Syndrome & 2019 [Rodrigues et al. 2019a, b] & _- \\
\hline 10 & FTIR & Neonatal sepsis using saliva & 2019 [Yunanto et al. 2019] & - \\
\hline 11 & ATR-FTIR & Multiple dental caries & 2018 [Seredin et al. 2018] & - \\
\hline 12 & Plasmonics & Hepatitis B & 2017 [Riedel et al. 2017] & - \\
\hline 13 & IR & $\begin{array}{l}\text { Saliva in healthy, chronic, } \\
\text { and aggressive periodontitis }\end{array}$ & 2017 [Saranya 2017] & - \\
\hline 14 & Plasmonics & Hepatitis B & 2016 [Riedel et al. 2016] & - \\
\hline 15 & FTIR & $\begin{array}{l}\text { Differentiation of chronic } \\
\text { and aggressive Periodontitis }\end{array}$ & 2016 [Simsek Ozek et al. 2016] & $82 \%$ \\
\hline 16 & ICP OES \& ICP MS & Periodontal diseases. & 2016 [Herman et al. 2016] & $\begin{array}{l}\text { L.O.D: } 0.007 \mu \mathrm{g} / 1 \\
\text { for } \mathrm{Pb} \text { and } 0.21 \\
\mu \mathrm{g} / \mathrm{l} \text { for } \mathrm{Fe}\end{array}$ \\
\hline 17 & Raman & $\begin{array}{l}\text { Myocardial Infarction. Saliva spectroscopy; } \\
\text { Multivariate analysis }\end{array}$ & 2015 [Cao et al. 2015] & $80.04 \%$ \\
\hline 18 & FTIR & $\begin{array}{l}\text { Saliva proteomic components in psoriatic } \\
\text { and diabetic patients }\end{array}$ & 2015 [Bottoni et al. 2015] & - \\
\hline 19 & Fluorescence & Lithium in Bipolar disorder & 2011 [Kim et al. 2011] & - \\
\hline 20 & SPR & Mucin, Gingivitis, Periodontitis & 2007 [Fernández-González et al. 2007] & - \\
\hline
\end{tabular}


Table 4 Selected references on use of photonics/optical spectroscopy-based studies on saliva for clinical and other applications. (Drugs)

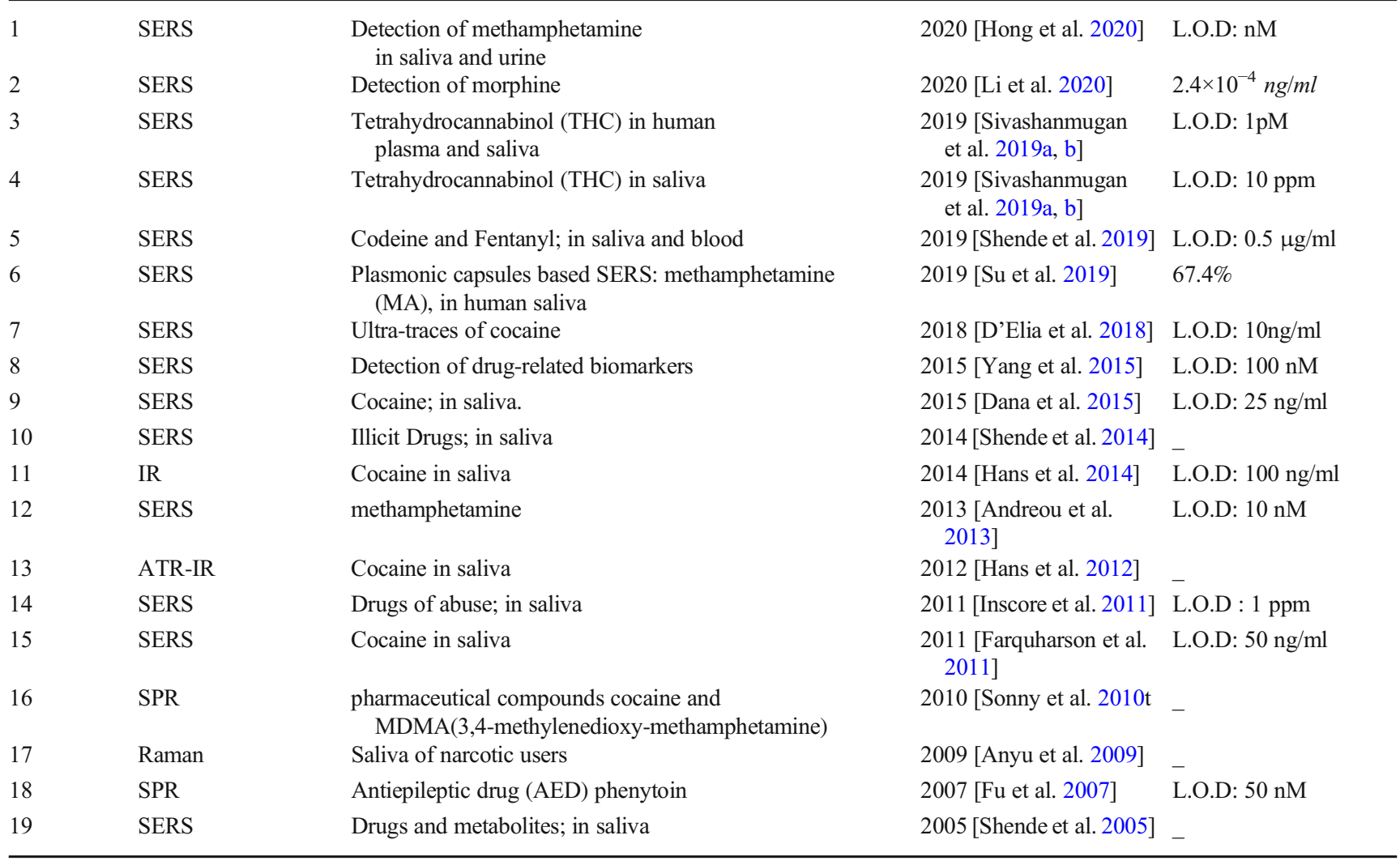

results. It is therefore, highly desirable to carry out studies to develop multi-modal spectral methods, especially where large number of samples have to be tested in short time intervals, since the multi-modal approach does not involve any additional time and same sample can be studied in different data analyses methods.

Table 5 Selected references on use of photonics/optical spectroscopy-based studies on saliva for clinical and other applications. (Other abnormal conditions)

\begin{tabular}{|c|c|c|c|c|}
\hline 1 & LSPR & Cortisol, stress biomarker & 2020 [Jo et al. 2020] & L.O.D: $0.1 \mathrm{nM}$ \\
\hline 2 & UV Absorption & Stress biomarkers in different body fluids & 2019 [Ray and Steckl 2019] & L.O.D of cortisol: $0.5 \mu \mathrm{M}$ \\
\hline 3 & SERS, LIF, SPR & Diseases, drugs, general health & 2019 [Ilea et al. 2019] & _- \\
\hline 4 & FTIR & Real-time checking of response to stress & 2016 [Caetano Júnior et al. 2016] & _- \\
\hline 5 & SPR & Hormones (Cortisol, Testosterone) & $\begin{array}{l}2014 \text { [Stevens et al. 2014, Mitchell } \\
\text { and Lowe 2009] }\end{array}$ & $\begin{array}{l}\text { L.O.D of cortisol: } 1 \mathrm{ng} / \mathrm{ml} \\
\text { L.O.D of Testosterone: } 29 \mathrm{pg} / \mathrm{ml}\end{array}$ \\
\hline 6 & SPR & Cortisol & 2014 [Tahara et al. 2014] & L.O.D: 38 ppt \\
\hline 7 & SPR & Cathespin G, Immune response & 2011 [Gorodkiewicz et al. 2011] & L.O.D: $0.12 \mathrm{ng} / \mathrm{ml}$ \\
\hline 8 & FTIR & $\begin{array}{l}\text { Saliva of normal and diabetic pregnant } \\
\text { women in each trimester. }\end{array}$ & 2011 [Sultana et al. 2011] & - \\
\hline 9 & SPR & Cathespin D & 2010 [Gorodkiewicz and Regulska 2010] & L.O.D: $0.12 \mathrm{ng} / \mathrm{ml}$ \\
\hline 10 & ATR-FTIR & $\begin{array}{l}\text { Saliva biomarker; exercise induced stress. } \\
\text { Real-time checking of response to stress. }\end{array}$ & 2010 [Khaustova et al. 2010] & - \\
\hline 11 & SPR & Cortisol and cortisone & 2009 [Frasconi et al. 2009] & L.O.D: $10 \mu \mathrm{g} / 1$ \\
\hline
\end{tabular}


Table 6 Selected references on use of photonics/optical spectroscopy-based studies on saliva for clinical and other applications. (Other applications)

\begin{tabular}{|c|c|c|c|c|}
\hline 1 & IR & Age and gender & 2020 [Bel'skaya et al. 2020] & \\
\hline 2 & AAS & Metal residuals in saliva: orthodontic Appliances & 2020 [Curro, and Bilello 2020] & L.O.D : $\mu \mathrm{g} / 1$ \\
\hline 3 & IR & $\begin{array}{l}\text { Spectral features in tobacco smoking, periodontal } \\
\text { diseases, and gender. }\end{array}$ & 2019 [Derruau et al. 2019] & - \\
\hline 4 & AAS & $\begin{array}{l}\text { Release of nickel, chromium, and zinc in saliva; } \\
\text { Use of orthodontic appliances }\end{array}$ & 2019 [Quadras et al. 2019] & _- \\
\hline 5 & SERS & Effects of low-dose irradiation on saliva & 2019 [Colceriu-Şimon et al. 2019] & _- \\
\hline 6 & LIBS & Calcium in saliva & 2019 [Zahroh et al. 2019] & - \\
\hline 7 & IR & Saliva composition & 2018 [Bel'skaya et al. 2018] & - \\
\hline 8 & ATR-FTIR & Forensic, body fluids, including Saliva & 2018 [Takamura et al. 2018] & - \\
\hline 9 & SPR & $\mathrm{ABH}$ antigen detection in saliva. & 2017 [Peungthum et al. 2017] & - \\
\hline 10 & LSPR & $\begin{array}{l}\text { Wine astringency. Interaction of red } \\
\text { wine and saliva }\end{array}$ & 2017 [Guerreiro et al. 2017] & L.O.D : $1 \mu \mathrm{mol} / \mathrm{L}$ \\
\hline 11 & LSPR & Monitoring the $\mathrm{pH}$ of saliva & 2017 [Luo et al. 2017] & $\begin{array}{l}\text { wavelengths of } 665 \mathrm{~nm} \text { and } 785 \\
\mathrm{~nm}-\text { the sensitivities were } \\
0.0299 \text { a.u. } / \mathrm{pH} \text { (a.u. }=\text { arbitrary unit) } \\
\text { with a linear range of } \mathrm{pH}=5-8 \\
\text { and } 0.0234 \text { a.u./pH with linear range } \\
\text { of } \mathrm{pH}=2-8, \text { respectively }\end{array}$ \\
\hline 12 & FTIR & Effect of smoking cessation on saliva & 2017 [Rodrigues et al. 2017] & _ \\
\hline 13 & TRLFS & $\begin{array}{l}\text { ingestion of radioactive contaminants, } \\
\text { time-resolved laser-induced } \\
\text { fluorescence spectroscopy }\end{array}$ & 2017 [Barkleit et al. 2017] & - \\
\hline 14 & Raman & Forensic body fluid identification & 2016 [Muro et al. 2016] & _ \\
\hline 15 & Raman & $\begin{array}{l}\text { Sex determination based on saliva } \\
\text { spectrum; forensic }\end{array}$ & 2016 [Muro et al. 2016a, b] & $\overline{9} 2 \%$ \\
\hline 16 & IR, Raman & Forensic analysis & 2015 [Zapata et al. 2015] & _- \\
\hline 17 & SPRi-MS & $\begin{array}{l}\text { Protein biomarkers salivary } \alpha \text {-amylase } \\
\text { and lysozyme. }\end{array}$ & 2015 [Musso et al. 2015] & - \\
\hline 18 & Raman & Forensic analysis & 2010 [Virkler and Lednev 2010] & _ \\
\hline
\end{tabular}

Acknowledgements The authors would like to acknowledge DST, DSTFIST, VGST, Govt. of Karnataka, I-CUP, Office of the Principle Scientific Advisor, Govt. of India, for various facilities extended for the studies discussed in this paper. J. Lukose likes to acknowledge Vittal Shenoy for his support.

Funding Open access funding provided by Manipal Academy of Higher Education, Manipal.

Open Access This article is licensed under a Creative Commons Attribution 4.0 International License, which permits use, sharing, adaptation, distribution and reproduction in any medium or format, as long as you give appropriate credit to the original author(s) and the source, provide a link to the Creative Commons licence, and indicate if changes were made. The images or other third party material in this article are included in the article's Creative Commons licence, unless indicated otherwise in a credit line to the material. If material is not included in the article's Creative Commons licence and your intended use is not permitted by statutory regulation or exceeds the permitted use, you will need to obtain permission directly from the copyright holder. To view a copy of this licence, visit http://creativecommons.org/licenses/by/4.0/.

\section{References}

Akçan R, YILDIRIM MȘ, Ilhan H, Güven B, Tamer U, Sağlam N (2020) Surface enhanced Raman spectroscopy as a novel tool for rapid quantification of heroin and metabolites in saliva. Turk J Med Sci. 50. https://doi.org/10.3906/sag-1912-196

Al-Muslet N, Ali E (2011) In vivo spectral analysis of bladder cancer using fourier transform infrared spectroscopy, a comparative study. Aust J Basic Appl 5:1734-1739

Alsamarai ATS, Husain AA, Saleh TA-K, Thabit NM (2018) Salivary cystatin $\mathrm{C}$ as a biochemical marker for chronic renal failure. Eurasian J Anal Chem 13(5). https://doi.org/10.29333/ejac/95168

Amano A, Nakamura T, Kimura S, Morisaki I, Nakagawa I, Kawabata S, Hamada S (1999) Molecular Interactions of Porphyromonas gingivalisFimbriae with Host Proteins: Kinetic Analyses Based on Surface Plasmon Resonance. Infect Immun 67(5):2399-2405. https://doi.org/10.1128/IAI.67.5.2399-2405.1999

Andreou C, Hoonejani MR, Barmi MR, Moskovits M, Meinhart CD (2013) Rapid detection of drugs of abuse in saliva using surface enhanced Raman spectroscopy and microfluidics. ACS Nano 7(8): 7157-7164. https://doi.org/10.1021/nn402563f

Anyu C, Lin H, Jinghua L, ZiJian C, Yi J, Dian Q, Xun G, Chunwei L, Wen H, Hong W (2009) Detecting narcotic usage using surfaceenhanced Raman spectroscopy on saliva samples. In: World Congress on Medical Physics and Biomedical Engineering, September 7-12, 2009, Munich, Germany, Springer. https://doi. org/10.1007/978-3-642-03885-3_20

Ayerden NP, Aygun U, Holmstrom ST, Olcer S, Can B, Stehle J-L, Urey H (2014) High-speed broadband FTIR system using MEMS. Appl Opt 53(31):7267-7272. https://doi.org/10.1364/AO.53.007267

Azzi L, Carcano G, Gianfagna F, Grossi P, Dalla Gasperina D, Genoni A, Fasano M, Sessa F, Tettamanti L, Carinci F (2020) Saliva is a 
reliable tool to detect SARS-CoV-2. J Inf Secur 81(1):e45-e50. https://doi.org/10.1016/j.jinf.2020.04.005

Bai H, Wang R, Hargis B, Lu H, Li Y (2012) A SPR aptasensor for detection of avian influenza virus H5N1. Sensors 12(9):1250612518. https://doi.org/10.3390/s120912506

Baker MJ, Faulds K (2016) Fundamental developments in clinical infrared and Raman spectroscopy. Chem Soc Rev 45(7):1792-1793. https://doi.org/10.1039/C6CS90028C

Balan V, Mihai C-T, Cojocaru F-D, Uritu C-M, Dodi G, Botezat D, Gardikiotis I (2019) Vibrational spectroscopy fingerprinting in medicine: From molecular to clinical practice. Materials 12(18):2884. https://doi.org/10.3390/ma12182884

Barkleit A, Wilke C, Heller A, Stumpf T, Ikeda-Ohno A (2017) Trivalent f-elements in human saliva: a comprehensive speciation study by time-resolved laser-induced fluorescence spectroscopy and thermodynamic calculations. Dalton Trans 46(5):1593-1605. https://doi. org/10.1039/c6dt03726g

Barzon L, Pacenti M, Berto A, Sinigaglia A, Franchin E, Lavezzo E, Brugnaro $P$, Palù $G$ (2016) Isolation of infectious Zika virus from saliva and prolonged viral RNA shedding in a traveller returning from the Dominican Republic to Italy, January 2016. Eurosurveillance 21(10):30159. https://doi.org/10.2807/15607917.ES.2016.21.10.30159

Bel'skaya L, Sarf E, Makarova N (2018) Use of Fourier transform IR spectroscopy for the study of saliva composition. J Appl Spectrosc 85(3):445-451. https://doi.org/10.1007/s10812-018-0670-0

Bel'skaya L, Sarf E, Gundyrev I (2019) Study of the IR spectra of the saliva of cancer patients. J Appl Spectrosc Retrieved 6:85. https:// doi.org/10.1007/s10812-019-00762-z

Bel'skaya LV, Sarf EA, Solomatin DV (2020) Age and Gender Characteristics of the Infrared Spectra of Normal Human Saliva. Appl Spectrosc 74(5):536-543

Belushkin A, Yesilkoy F, González-López JJ, Ruiz-Rodríguez JC, Ferrer R, Fàbrega A, Altug H (2020) Rapid and digital detection of inflammatory biomarkers enabled by a novel portable nanoplasmonic imager. Small 16(3):1906108. https://doi.org/10.1002/smll.201906108

Beyer-Hans KMC, Sigrist MW, Silbereisen A, Ozturk VO, Emingil G, Bostanci N (2020) Salivary Fingerprinting of Periodontal Disease by Infrared-ATR Spectroscopy. Proteomics Clin Appl 14(3): 1900092. https://doi.org/10.1002/prca.201900092

Bigler LR, Streckfus CF, Dubinsky WP (2009) Salivary biomarkers for the detection of malignant tumors that are remote from the oral cavity. Clin Lab Med 29(1):71-85. https://doi.org/10.1016/j.cll. 2009.01.004

Bilello GCAG (2020) Quantitative and Qualitative in vivo Analysis of Metal Residuals in the Saliva of Subjects with and without Fixed Orthodontic Appliances. Biomed J Sci Tech Res 26:19617-19621. https://doi.org/10.26717/BJSTR.2020.26.004291

Bioptics World Editors (2020) Optical method could cut Coronavirus diagnosis time to 15 minutes. World, BioOptics from https://www. bioopticsworld.com/biophotonics-techniques/article/14169448/ optical-method-could-cut-coronavirus-diagnosis-time-to-15minutes

Bishop JL, Bell JF III, Moersch JE (2019) Remote Compositional Analysis: Techniques for Understanding Spectroscopy, Mineralogy, and Geochemistry of Planetary Surfaces. Cambridge University Press

Bonifacio A, Cervo S, Sergo V (2015) Label-free surface-enhanced Raman spectroscopy of biofluids: fundamental aspects and diagnostic applications. Anal Bioanal Chem 407(27):8265-8277. https:// doi.org/10.1007/s00216-015-8697-z

Bottoni U, Tiriolo R, Pullano SA, Dastoli S, Amoruso GF, Nisticò SP, Fiorillo AS (2015) Infrared saliva analysis of psoriatic and diabetic patients: similarities in protein components. IEEE Trans Biomed Eng 63(2):379-384. https://doi.org/10.1109/TBME.2015.2458967
Bourouiba L (2020) Turbulent gas clouds and respiratory pathogen emissions: potential implications for reducing transmission of COVID19. Jama 323(18):1837-1838. https://doi.org/10.1001/jama.2020. 4756

Bunaciu AA, Fleschin S, Hoang VD, Aboul-Enein HY (2017) Vibrational spectroscopy in body fluids analysis. Crit Rev Anal Chem 47(1):67-75. https://doi.org/10.1080/10408347.2016. 1209104

Caetano Júnior PC, Lemes LC, Aguiar JC, Strixino JF, Raniero L (2016) Application of FT-IR spectroscopy to assess physiological stress in rugby players during fatigue test. Res Biomed Eng 32(2):123-128. https://doi.org/10.1590/2446-4740.05315

Cai F, Wang D, Zhu M, He S (2017) Pencil-like imaging spectrometer for bio-samples sensing. Biomed Opt Express 8(12):5427-5436. https://doi.org/10.1364/BOE.8.005427

Cao G, Chen M, Chen Y, Huang Z, Lin J, Lin J, Xu Z, Wu S, Huang W, Weng $G$ (2015) A potential method for non-invasive acute myocardial infarction detection based on saliva Raman spectroscopy and multivariate analysis. Laser Phys Lett 12(12):125702. https://doi. org/10.1088/1612-2011/12/12/125702/meta

Carlomagno C, Banfi P, Gualerzi A, Picciolini S, Volpato E, Meloni M, Lax A, Colombo E, Ticozzi N, Verde F (2020) Human salivary Raman fingerprint as biomarker for the diagnosis of Amyotrophic Lateral Sclerosis. Sci Rep 10(1):1-13. https://doi.org/10.1038/ s41598-020-67138-8

Ceron JJ, Lamy E, Martinez-Subiela S, Lopez-Jornet P, Capela e Silva F, Eckersall PD, Tvarijonaviciute A (2020) Use of Saliva for Diagnosis and Monitoring the SARS-CoV-2: A General Perspective. Clin Med 9(5):1491. https://doi.org/10.3390/jcm9051491

Chai J, Zhang K, Xue Y, Liu W, Chen T, Lu Y, Zhao G (2020) Review of MEMS Based Fourier Transform Spectrometers. Micromachines 11(2):214. https://doi.org/10.3390/mi1 1020214

Chiang C-Y, Chen C (2019) Toward characterizing extracellular vesicles at a single-particle level. J Biomed Sci 26(1):1-10. https://doi.org/ 10.1186/s12929-019-0502-4

Chidangil S, Dharmadhikari AK, Alti K, Dharmadhikari JA, Mathur D (2007) Suppression of ultrafast supercontinuum generation in a salivary protein. J Biomed Opt 12(2):020510. https://doi.org/10.1117/ 1.2731316

Choi J-H, Lee J-H, Son J, Choi J-W (2020) Noble Metal-Assisted Surface Plasmon Resonance Immunosensors. Sensors 20(4):1003. https:// doi.org/10.3390/s20041003

Chojnowska S, Baran T, Wilińska I, Sienicka P, Cabaj-Wiater I, Knaś M (2018) Human saliva as a diagnostic material. Adv Med Sci 63(1): 185-191. https://doi.org/10.1016/j.advms.2017.11.002

Colceriu-Șimon IM, Hedeșiu M, Toma V, Armencea G, Moldovan A, Știufiuc G, Culic B, ărmure V, Dinu C, Berindan-Neagoe I (2019) The Effects of Low-Dose Irradiation on Human Saliva: A SurfaceEnhanced Raman Spectroscopy Study. Diagnostics 9(3):101. https://doi.org/10.3390/diagnostics9030101

Cordero E, Latka I, Matthäus C, Schie IW, Popp J (2018) In-vivo Raman spectroscopy: from basics to applications. J Biomed Opt 23(7): 071210. https://doi.org/10.1117/1.JBO.23.7.071210

Cui F, Zhou HS (2020) Diagnostic methods and potential portable biosensors for coronavirus disease 2019. Biosens Bioelectron 165: 112349. https://doi.org/10.1016/j.bios.2020.112349

D'Elia V, Rubio-Retama J, Ortega-Ojeda FE, García-Ruiz C, Montalvo G (2018) Gold nanorods as SERS substrate for the ultratrace detection of cocaine in non-pretreated oral fluid samples. Colloids Surf A Physicochem Eng Asp 557:43-50. https://doi.org/10.1016/j. colsurfa.2018.05.068

Dana K, Shende C, Huang H, Farquharson S (2015) Rapid analysis of cocaine in saliva by surface-enhanced Raman spectroscopy. J Anal Bioanal Tech 6(6):1. https://doi.org/10.4172/2155-9872.1000289

Daniel A, Calado G, Behl I, Flint S, Galvin S, Healy C, Byrne HJ, Lyng FM (2020) Comparative study of oral dysplasia by conventional and 
surface enhanced Raman spectroscopy of whole saliva. Biomedical Vibrational Spectroscopy 2020: Advances in Research and Industry, International Society for Optics and Photonics 11236. https://doi. org/10.1117/12.2539545

de Jesús Zermeño-Nava J, Martínez-Martínez MU, Rámirez-de-Ávila AL, Hernández-Arteaga AC, García-Valdivieso MG, HernándezCedillo A, José-Yacamán M, Navarro-Contreras HR (2018) Determination of sialic acid in saliva by means of surfaceenhanced Raman spectroscopy as a marker in adnexal mass patients: ovarian cancer vs benign cases. J Ovarian Res 11(1):61. https://doi. org/10.1186/s13048-018-0433-9

Dekel BZ, A. Z.-H, Malonek D, Yahalom R, Vered M (2019) Oral Cancer Diagnostics using FTIR-ATR Spectra of Salivary Exosomes: A Preliminary Study. In: Proceedings of the 5th World Congress on Electrical Engineering and Computer Systems and Sciences (EECSS'19). https://doi.org/10.11159/icbes19.109

Derruau S, Gobinet C, Mateu A, Untereiner V, Lorimier S, Piot O (2019) Shedding light on confounding factors likely to affect salivary infrared biosignatures. Anal Bioanal Chem 411(11):2283-2290. https://doi.org/10.1007/s00216-019-01669-6

Desai S, Mishra SV, Joshi A, Sarkar D, Hole A, Mishra R, Dutt S, Chilakapati MK, Gupta S, Dutt A (2020) Raman spectroscopybased detection of RNA viruses in saliva: A preliminary report. J Biophotonics 13(10):e202000189. https://doi.org/10.1002/jbio. 202000189

Dhanada VS, George SD, Kartha VB, Chidangil S, Unnikrishnan VK (2020) Hybrid LIBS-Raman-LIF systems for multi-modal spectroscopic applications: a topical review. Appl Spectrosc Rev 1-29. https://doi.org/10.1080/05704928.2020.1800486

Díaz-Liñán M, García-Valverde M, López-Lorente A, Cárdenas S, Lucena R (2020) Silver nanoflower-coated paper as dual substrate for surface-enhanced Raman spectroscopy and ambient pressure mass spectrometry analysis. Anal Bioanal Chem 412:3547-3557. https://doi.org/10.1007/s00216-020-02603-x

Endo T, Ozawa S, Okuda N, Yanagida Y, Tanaka S, Hatsuzawa T (2010) Reflectometric detection of influenza virus in human saliva using nanoimprint lithography-based flexible two-dimensional photonic crystal biosensor. Sens Actuators, B 148(1):269-276. https://doi. org/10.1016/j.snb.2010.05.036

Eom G, Hwang A, Kim H, Yang S, Lee DK, Song S, Ha K, Jeong J, Jung J, Lim E-K (2019) Diagnosis of Tamiflu-Resistant Influenza Virus in Human Nasal Fluid and Saliva Using Surface-Enhanced Raman Scattering. ACS Sens 4(9):2282-2287. https://doi.org/10.1021/ acssensors.9b00697

Falamas A, Faur C, Baciut M, Rotaru H, Chirila M, Cinta Pinzaru S, Hedesiu M (2020) Raman Spectroscopic Characterization of Saliva for the Discrimination of Oral Squamous Cell Carcinoma. Anal Lett 54(1-2):57-69. https://doi.org/10.1080/00032719.2020. 1719129

Fălămaș A, Rotaru H, Hedeșiu M (2020) Surface-enhanced Raman spectroscopy (SERS) investigations of saliva for oral cancer diagnosis. Lasers Med Sci 35:1393-1401. https://doi.org/10.1007/s10103020-02988-2

Farago P, Băbțan A-M, Galatus R, Groza R, Roman N, Feurdean C, Ilea A (2019) A side-polished fluorescent fiber sensor for the detection of blood in the saliva. In: 6th International Conference on Advancements of Medicine and Health Care through Technology; 17-20 October 2018, Cluj-Napoca, Romania, Springer, vol 71, pp 23-28. https://doi.org/10.1007/978-981-13-6207-1_4

Farah R, Haraty H, Salame Z, Fares Y, Ojcius DM, Sadier NS (2018) Salivary biomarkers for the diagnosis and monitoring of neurological diseases. Biomed.J. 41(2):63-87. https://doi.org/10.1016/j.bj. 2018.03.004

Farquharson S, Shende C, Inscore FE, Maksymiuk P, Gift A (2005) Analysis of 5-fluorouracil in saliva using surface-enhanced Raman spectroscopy. J Raman Spectrosc 36(3):208-212. https://doi.org/10. $1002 /$ jrs. 1277

Farquharson S, Gift A, Shende C, Inscore F, Ordway B, Farquharson C, Murren J (2008) Surface-enhanced Raman spectral measurements of 5-fluorouracil in saliva. Molecules. 13(10):2608-2627. https:// doi.org/10.3390/molecules 13102608

Farquharson S, Shende C, Sengupta A, Huang H, Inscore F (2011) Rapid detection and identification of overdose drugs in saliva by surfaceenhanced Raman scattering using fused gold colloids. Pharmaceutics 3(3):425-439. https://doi.org/10.3390/ pharmaceutics3030425

FDA (2020) "Drug Administration. Accelerated Emergency Use Authorization (EUA) Summary SARS-CoV-2 Assay (Rutgers Clinical Genomics Laboratory)." FDA, US: 1-8

Feng S, Huang S, Lin D, Chen G, Xu Y, Li Y, Huang Z, Pan J, Chen R, Zeng H (2015) Surface-enhanced Raman spectroscopy of saliva proteins for the noninvasive differentiation of benign and malignant breast tumors. Int J Nanomedicine 10:537-547. https://doi.org/10. 2147/IJN.S71811

Fernández-González A, Rychłowska J, Badía R, Salzer R (2007) SPR imaging as a tool for detecting mucin-anti-mucin interaction. Outline of the development of a sensor for near-patient testing for mucin. Microchim Acta 158(3-4):219-225. https://doi.org/10.1007/ s00604-006-0698-3

Ferreira IC, Aguiar EM, Silva AT, Santos LL, Cardoso-Sousa L, Araújo TG, Santos DW, Goulart LR, Sabino-Silva R, Maia YC (2020) Attenuated Total Reflection-Fourier Transform Infrared (ATRFTIR) Spectroscopy Analysis of Saliva for Breast Cancer Diagnosis. J.Oncol. 2020. https://doi.org/10.1155/2020/4343590

Frasconi M, Mazzarino M, Botrè F, Mazzei F (2009) Surface plasmon resonance immunosensor for cortisol and cortisone determination. Anal Bioanal Chem 394(8):2151-2159. https://doi.org/10.1007/ s00216-009-2914-6

Fu E, Chinowsky T, Nelson K, Johnston K, Edwards T, Helton K, Grow M, Miller JW, Yager P (2007) SPR imaging-based salivary diagnostics system for the detection of small molecule analytes. Ann N Y Acad Sci 1098(1):335-344. https://doi.org/10.1196/annals.1384. 026

Gabbarini V, Rossi R, Ciparisse J, Puleio A, Malizia A, Gaudio P (2019) An UltraViolet Laser-Induced Fluorescence (UV-LIF) system to detect, identify and measure the concentration of biological agents in the environment: a preliminary study. J Instrum 14(07):C07009. https://doi.org/10.1088/1748-0221/14/07/C07009/meta

George T, Honnamurthy JB, Shivashankara AR, Suresh S, Baliga MS (2017) Correlation of Blood and Salivary Levels of Zinc, Iron and Copper in Head and Neck Cancer Patients: An Investigational Study. Avicenna Journal of Medical Biochemistry 5(1):35-39. https://doi.org/10.15171/ajmb.2017.06

Gorodkiewicz E, Luszczyn J (2011) Surface Plasmon Resonance Imaging (SPRI) sensor for cystatin determination based on immobilized papain. Protein Pept Lett 18(1):23-29. https://doi.org/ $10.2174 / 092986611794328663$

Gorodkiewicz E, Regulska E (2010) SPR imaging biosensor for aspartyl cathepsins: sensor development and application for biological material. Protein Pept Lett 17(9):1148-1154. https://doi.org/10.2174/ 092986610791760450

Gorodkiewicz E, Regulska E, Wojtulewski K (2011) Development of an SPR imaging biosensor for determination of cathepsin $\mathrm{G}$ in saliva and white blood cells. Microchim Acta 173(3-4):407-413. https:// doi.org/10.1007/s00604-011-0569-4

Guerreiro JRL, Teixeira N, De Freitas V, Sales MGF, Sutherland DS (2017) A saliva molecular imprinted localized surface plasmon resonance biosensor for wine astringency estimation. Food Chem 233: 457-466. https://doi.org/10.1016/j.foodchem.2017.04.051

Gug IT, Tertis M, Hosu O, Cristea C (2019) Salivary biomarkers detection: Analytical and immunological methods overview. TrAC, 
Trends Anal Chem 113:301-316. https://doi.org/10.1016/j.trac. 2019.02.020

Guilbault GG, Palleschi G, Lubrano G (1995) Non-invasive biosensors in clinical analysis. Biosens Bioelectron 10(3-4):379-392. https://doi. org/10.1016/0956-5663(95)96856-T

Han Z, Liu H, Meng J, Yang L, Liu J, Liu J (2015) Portable kit for identification and detection of drugs in human urine using surfaceenhanced Raman spectroscopy. Anal Chem 87(18):9500-9506. https://doi.org/10.1021/acs.analchem.5b02899

Han S, Locke AK, Oaks LA, Cheng Y-SL, Coté GL (2019) Nanoparticlebased assay for detection of S100P mRNA using surface-enhanced Raman spectroscopy. J Biomed Opt 24(5):055001. https://doi.org/ 10.1117/1.JBO.24.5.055001

Hans KM-C, Gianella M, Sigrist MW (2012) Sensing cocaine in saliva with attenuated total reflection infrared (ATR-IR) spectroscopy combined with a one-step extraction method. Optical Diagnostics and Sensing XII: Toward Point-of-Care Diagnostics; and Design and Performance Validation of Phantoms Used in Conjunction with Optical Measurement of Tissue IV, International Society for Optics and Photonics 8229. https://doi.org/10.1117/12.906207

Hans KM-C, Müller M, Petrosyan T, Sigrist MW (2014) Infrared detection of cocaine and street cocaine in saliva with a one-step extraction. Anal Methods 6(3):666-673. https://doi.org/10.1039/ C3AY41285G

Herman M, Golasik M, Piekoszewski W, Walas S, Napierala M, Wyganowska-Swiatkowska M, Kurhanska-Flisykowska A, Wozniak A, Florek E (2016) Essential and toxic metals in oral fluid-a potential role in the diagnosis of periodontal diseases. Biol Trace Elem Res 173(2):275-282. https://doi.org/10.1007/s12011016-0660-0

Hernández-Arteaga A, Nava JDJZ, Kolosovas-Machuca ES, VelázquezSalazar JJ, Vinogradova E, José-Yacamán M, Navarro-Contreras HR (2017) Diagnosis of breast cancer by analysis of sialic acid concentrations in human saliva by surface-enhanced Raman spectroscopy of silver nanoparticles. Nano Res 10(11):3662-3670. https://doi.org/10.1007/s12274-017-1576-5

Hernández-Cedillo A, García-Valdivieso MG, Hernández-Arteaga AC, Patiño-Marín N, Vértiz-Hernández ÁA, José-Yacamán M, NavarroContreras HR (2019) Determination of sialic acid levels by using surface-enhanced Raman spectroscopy in periodontitis and gingivitis. Oral Dis 25(6):1627-1633. https://doi.org/10.1111/odi.13141

Homola J (2003) Present and future of surface plasmon resonance biosensors. Anal Bioanal Chem 377(3):528-539. https://doi.org/10. 1007/s00216-003-2101-0

Homola J, Piliarik M (2006) Surface plasmon resonance (SPR) sensors. Springer 4:45-67. https://doi.org/10.1007/5346_014

Hong Y, Zhou X, Xu B, Huang Y, He W, Wang S, Wang C, Zhou G, Chen Y, Gong T (2020) Optoplasmonic Hybrid Materials for Trace Detection of Methamphetamine in Biological Fluids through SERS. ACS Appl Mater Interfaces 12(21):24192-24200. https://doi.org/ 10.1021/acsami.0c00853

Hu S, Gao Y, Wu Y, Guo X, Ying Y, Wen Y, Yang H (2019) Raman tracking the activity of urease in saliva for healthcare. Biosens Bioelectron 129:24-28. https://doi.org/10.1016/j.bios.2018.12.059

Ilea A, Andrei V, Feurdean CN, Băbțan A-M, Petrescu NB, Câmpian RS, Boşca AB, Ciui B, Tertiș M, Săndulescu R (2019) Saliva, a magic biofluid available for multilevel assessment and a mirror of general health—A systematic review. Biosensors 9(1):27. https://doi.org/10. 3390/bios 9010027

Inscore F, Shende C, Sengupta A, Huang H, Farquharson S (2011) Detection of drugs of abuse in saliva by surface-enhanced Raman spectroscopy (SERS). Appl Spectrosc 65(9):1004-1008. https://doi. org/10.1366/11-06310

Isaza-Guzmán DM, Arias-Osorio C, Martínez-Pabón MC, TobónArroyave SI (2011) Salivary levels of matrix metalloproteinase (MMP)-9 and tissue inhibitor of matrix metalloproteinase (TIMP)-
1: A pilot study about the relationship with periodontal status and MMP-9- $1562 \mathrm{C} / \mathrm{T}$ gene promoter polymorphism. Arch Oral Biol 56(4):401-411. https://doi.org/10.1016/j.archoralbio.2010.10.021

Jinglin H, Minjie Z, Wei L, Guo C, Shuang N, Gao N, Zeyu L, Zongqing Z, Zhibing H, Bo L (2020) Detection of spike protein of SARSCoV-2 by surface enhanced Raman spectroscopy. High Power Laser Part. Beams 32(6):069001-069001-069001-069002. https:// doi.org/10.11884/HPLPB202032.200145

Jo S, Lee W, Park J, Kim W, Kim W, Lee G, Lee H-J, Hong J, Park J (2020) Localized surface plasmon resonance aptasensor for the highly sensitive direct detection of cortisol in human saliva. Sensors Actuators B Chem 304:127424. https://doi.org/10.1016/j. snb.2019.127424

Jokerst JV, Raamanathan A, Christodoulides N, Floriano PN, Pollard AA, Simmons GW, Wong J, Gage C, Furmaga WB, Redding SW (2009) Nano-bio-chips for high performance multiplexed protein detection: determinations of cancer biomarkers in serum and saliva using quantum dot bioconjugate labels. Biosens Bioelectron 24(12): 3622-3629. https://doi.org/10.1016/j.bios.2009.05.026

Joudah LN, Husain HH, Hassan MB (2018) Study serum and saliva samples of leukemic and compare them with Normal Objects by UV-Visible Spectroscopy. J Kufa Phys 10(1):130-142. https://doi. org/10.31257/2018/JKP/100118

Kaczor-Urbanowicz KE, Martin Carreras-Presas C, Aro K, Tu M, GarciaGodoy F, Wong DT (2017) Saliva diagnostics-Current views and directions. Exp Biol Med 242(5):459-472. https://doi.org/10.1177/ 1535370216681550

Kaczor-Urbanowicz KE, Wei F, Rao SL, Kim J, Shin H, Cheng J, Tu M, Wong DT, Kim Y (2019) Clinical validity of saliva and novel technology for cancer detection. Biochim Biophys Acta Rev Cancer 1872(1):49-59. https://doi.org/10.1016/j.bbcan.2019.05.007

Katsani KR, Sakellari D (2019) Saliva proteomics updates in biomedicine. J Biol Res-Thessalon 26(1):17. https://doi.org/10.1186/ s40709-019-0109-7

Khaustova S, Shkurnikov M, Tonevitsky E, Artyushenko V, Tonevitsky A (2010) Noninvasive biochemical monitoring of physiological stress by Fourier transform infrared saliva spectroscopy. Analyst 135(12):3183-3192. https://doi.org/10.1039/C0AN00529K

Khurshid Z, Zohaib S, Najeeb S, Zafar MS, Slowey PD, Almas K (2016) Human saliva collection devices for proteomics: An update. Int J Mol Sci 17(6):846. https://doi.org/10.3390/ijms17060846

Khurshid Z, Zafar M, Khan E, Mali M, Latif M (2019) Human saliva can be a diagnostic tool for Zika virus detection. J Infect Public Health 12(5):601-604. https://doi.org/10.1016/j.jiph.2019.05.004

Kim JH, Diamond D, Lau KT (2011) Optical device for non-invasive monitoring of lithium in bipolar disorder patients. In: 5th European Conference of the International Federation for Medical and Biological Engineering, vol 37. Springer, pp 979-982. https://doi. org/10.1007/978-3-642-23508-5_255

Kim SY, Khanal D, Tharkar P, Kalionis B, Chrzanowski W (2018) None of us is the same as all of us: resolving the heterogeneity of extracellular vesicles using single-vesicle, nanoscale characterization with resonance enhanced atomic force microscope infrared spectroscopy (AFM-IR). Nanoscale Horiz 3(4):430-438. https://doi.org/10. 1039/C8NH00048D

Kim K, Choi N, Jeon JH, Rhie G-e, Choo J (2019a) SERS-based immunoassays for the detection of botulinum toxins $\mathrm{A}$ and $\mathrm{B}$ using magnetic beads. Sensors 19(19):4081. https://doi.org/10.3390/ s19194081

Kim SY, Khanal D, Kalionis B, Chrzanowski W (2019b) High-fidelity probing of the structure and heterogeneity of extracellular vesicles by resonance-enhanced atomic force microscopy infrared spectroscopy. Nat Protoc 14(2):576-593. https://doi.org/10.1038/s41596018-0109-3

Kim Y-I, Kim S-G, Kim S-M, Kim E-H, Park S-J, Yu K-M, Chang J-H, Kim EJ, Lee S, Casel MAB (2020) Infection and rapid transmission 
of SARS-CoV-2 in ferrets. Cell Host Microbe 27(5):704-709. e702. https://doi.org/10.1016/j.chom.2020.03.023

Kneipp K, Kneipp H, Kartha VB, Manoharan R, Deinum G, Itzkan I, Dasari RR, Feld MS (1998) Detection and identification of a single DNA base molecule using surface-enhanced Raman scattering (SERS). Phys Rev E 57(6):R6281. https://doi.org/10.1103/ PhysRevE.57.R6281

Ko W-C, Rolain J-M, Lee N-Y, Chen P-L, Huang C-T, Lee P-I, Hsueh P$\mathrm{R}$ (2020) Arguments in favour of remdesivir for treating SARSCoV-2 infections. Int J Antimicro Ag 55(4):105933. https://doi. org/10.1016/j.ijantimicag.2020.105933

Krafft C (2016) Modern trends in biophotonics for clinical diagnosis and therapy to solve unmet clinical needs. J Biophotonics 9(11-12): 1362-1375. https://doi.org/10.1002/jbio.201600290

Krafft C, Wilhelm K, Eremin A, Nestel S, von Bubnoff N, SchultzeSeemann W, Popp J, Nazarenko I (2017) A specific spectral signature of serum and plasma-derived extracellular vesicles for cancer screening. Nanomedicine 13(3):835-841. https://doi.org/10.1016/j. nano.2016.11.016

Kruzelecky RV, Haddad E, Wong B, Lafrance D, Jamroz W, Ghosh AK, Zheng W, Phong L (2017) Miniature high-performance infrared spectrometer for space applications. In: International Conference on Space Optics-ICSO 2004, International Society for Optics and Photonics. 10568: Toulouse, France. https://doi.org/10.1117/ 12.2307999

Kumar P, Singh A, Kanaujia SK, Pradhan A (2018) Human saliva for oral precancer detection: a comparison of fluorescence \& stokes shift spectroscopy. J Fluoresc 28(1):419-426. https://doi.org/10.1007/ s10895-017-2203-2

Langer J, Jimenez de Aberasturi D, Aizpurua J, Alvarez-Puebla RA, Auguié B, Baumberg JJ, Bazan GC, Bell SE, Boisen A, Brolo AG (2019) Present and future of surface-enhanced Raman scattering. ACS Nano 14(1):28-117. https://doi.org/10.1021/acsnano.9b04224

Lednev IK (2019) Deep-Ultraviolet Raman Spectroscopy for Cancer Diagnostics: A Feasibility Study with Cell Lines and Tissues. Cancer Stud Mol Med Open J. 5(1):1-10. https://doi.org/10. 17140/CSMMOJ-5-126

Li X, Yang T, Li S, Yu T (2011) Surface-enhanced Raman spectroscopy differences of saliva between lung cancer patients and normal people. In: European Conference on Biomedical Optics, Optical Society of America. 808722. Munich Germany. https://doi.org/10.1364/ ECBO.2011.808722

Li W, Li X, Yang T, Guo X, Song Y (2020) Detection of saliva morphine using surface-enhanced Raman spectroscopy combined with immunochromatographic assay. J Raman Spectrosc 51(4):642648. https://doi.org/10.1002/jrs.5822

Liang Y-H, Chang C-C, Chen C-C, Chu-Su Y, Lin C-W (2012) Development of an $\mathrm{Au} / \mathrm{ZnO}$ thin film surface plasmon resonancebased biosensor immunoassay for the detection of carbohydrate antigen 15-3 in human saliva. Clin Biochem 45(18):1689-1693. https://doi.org/10.1016/j.clinbiochem.2012.09.001

Liedberg B, Nylander C, Lundström I (1995) Biosensing with surface plasmon resonance - how it all started. Biosens Bioelectron 10(8): i-ix. https://doi.org/10.1016/0956-5663(95)96965-2

Liu H, Delgado MR (1999) Therapeutic drug concentration monitoring using saliva samples. Clin Pharmacokinet 36(6):453-470. https:// doi.org/10.2165/00003088-199936060-00006

Liu L, Wei Q, Alvarez X, Wang H, Du Y, Zhu H, Jiang H, Zhou J, Lam P, Zhang L (2011) Epithelial cells lining salivary gland ducts are early target cells of severe acute respiratory syndrome coronavirus infection in the upper respiratory tracts of rhesus macaques. J Virol 85(8): 4025-4030. https://doi.org/10.1128/JVI.02292-10

Liu X, Yu H, Qiao Y, Yang J, Shu J, Zhang J, Zhang Z, He J, Li Z (2018) Salivary glycopatterns as potential biomarkers for screening of early-stage breast cancer. EBioMedicine 28:70-79. https://doi.org/ 10.1016/j.ebiom.2018.01.026
Lukose J, Kulal V, Chidangil S, Sinha R (2016) Smaller to larger biomolecule detection using a lab-built surface plasmon resonance based instrument. Laser Phys 26(10):105602. https://doi.org/10. 1088/1054-660X/26/10/105602/meta

Lukose J, Shetty V, Ballal M, Chidangil S, Sinha RK (2018) Real-time and rapid detection of Salmonella Typhimurium using an inexpensive lab-built surface plasmon resonance setup. Laser Phys Lett 15(7):075701. https://doi.org/10.1088/1612-202X/aabed8/meta

Luo C, Wang Y, Li X, Jiang X, Gao P, Sun K, Zhou J, Zhang Z, Jiang Q (2017) An optical sensor with polyaniline-gold hybrid nanostructures for monitoring $\mathrm{pH}$ in saliva. Nanomaterials 7(3):67. https:// doi.org/10.3390/nano 7030067

Malon RS, Sadir S, Balakrishnan M, Córcoles EP (2014) Saliva-based biosensors: noninvasive monitoring tool for clinical diagnostics. BioMed Res Int. 2014. https://doi.org/10.1155/2014/962903

Mandrile L, Rotunno S, Miozzi L, Vaira AM, Giovannozzi AM, Rossi AM, Noris E (2019) Nondestructive Raman Spectroscopy as a Tool for Early Detection and Discrimination of the Infection of Tomato Plants by Two Economically Important Viruses. Anal.Chem. 91(14):9025-9031. https://doi.org/10.1021/acs.analchem.9b01323

Masson J-F (2020) Portable and field-deployed surface plasmon resonance and plasmonic sensors. Analyst 145(11):3776-3800. https:// doi.org/10.1039/D0AN00316F

Mihály J, Deák R, Szigyártó IC, Bóta A, Beke-Somfai T, Varga Z (2017) Characterization of extracellular vesicles by IR spectroscopy: fast and simple classification based on amide and $\mathrm{CH}$ stretching vibrations. Biochim Biophys Acta Biomembr 1859(3):459-466. https:// doi.org/10.1016/j.bbamem.2016.12.005

Mitchell JS, Lowe TE (2009) Ultrasensitive detection of testosterone using conjugate linker technology in a nanoparticle-enhanced surface plasmon resonance biosensor. Biosens.Bioelectron. 24(7): 2177-2183. https://doi.org/10.1016/j.bios.2008.11.018

Mitchell JS, Lowe TE, Ingram JR (2009) Rapid ultrasensitive measurement of salivary cortisol using nano-linker chemistry coupled with surface plasmon resonance detection. Analyst 134(2):380-386. https://doi.org/10.1039/B817083P

Mohseni S, Moghadam TT, Dabirmanesh B, Jabbari S, Khajeh K (2016) Development of a label-free SPR sensor for detection of matrixmetalloproteinase- 9 by antibody immobilization on carboxymethyldextran chip. Biosens.Bioelectron 81:510-516. https://doi.org/10.1016/j.bios.2016.03.038

Moisoiu V, Badarinza M, Stefancu A, Iancu SD, Serban O, Leopold N, Fodor D (2020) Combining surface-enhanced Raman scattering (SERS) of saliva and two-dimensional shear wave elastography (2D-SWE) of the parotid glands in the diagnosis of Sjögren's syndrome. Spectrochim Acta, Part A 235:118267. https://doi.org/10. 1016/j.saa.2020.118267

Muro CK, de Souza Fernandes L, Lednev IK (2016a) Sex determination based on Raman spectroscopy of saliva traces for forensic purposes. Anal Chem 88(24):12489-12493. https://doi.org/10.1021/acs. analchem.6b03988

Muro CK, Doty KC, de Souza Fernandes L, Lednev IK (2016b) Forensic body fluid identification and differentiation by Raman spectroscopy. Forensic Chem 1:31-38. https://doi.org/10.1016/j.forc.2016.06.003

Musso J, Buchmann W, Gonnet F, Jarroux N, Bellon S, Frydman C, Brunet D-L, Daniel R (2015) Biomarkers probed in saliva by surface plasmon resonance imaging coupled to matrix-assisted laser desorption/ionization mass spectrometry in array format. Anal Bioanal Chem 407(5):1285-1294. https://doi.org/10.1007/s00216014-8373-8

Naseer K, Ali S, Qazi J (2020) ATR-FTIR spectroscopy as the future of diagnostics: a systematic review of the approach using bio-fluids. Appl.Spectrosc.Rev 56(2):85-97. https://doi.org/10.1080/ 05704928.2020 .1738453

Nganou C, Carrier A, Yang D, Chen Y, Yu N, Richards D, Bennett C, Oakes K, MacQuarrie S, Zhang X (2019) Effective plasmonic 
coupling and propagation facilitates ultrasensitive and remote sensing using Surface Enhanced Raman Spectroscopy. https://doi.org/ 10.26434/chemrxiv.11369820

Niedrig M, Patel P, Abd El Wahed A, Schädler R, Yactayo S (2018) Find the right sample: A study on the versatility of saliva and urine samples for the diagnosis of emerging viruses. BMC Infect Dis 18(1):114. https://doi.org/10.1186/s12879-018-3611-x

Nogueira MS (2020) Biophotonic telemedicine for disease diagnosis and monitoring during pandemics: overcoming COVID-19 and shaping the future of healthcare. Photodiagn Photodyn Ther 31. https://doi. org/10.1016/j.pdpdt.2020.101836

Okade AR, Hallikeri KS, Trivedi DJ (2015) Salivary estimation of copper, iron, zinc and manganese in oral submucous fibrosis patients: A case-control study. Clin Cancer Invest J 4(3):302-306. https://doi. org/10.4103/2278-0513.156075

Othman NH, Lee KY, Radzol ARM, Mansor W, Yusoff NA (2019) PCA-Polynomial-ELM Model Optimal for Detection of NS1 Adulterated Salivary SERS Spectra. Journal of Physics: Conference Series, IOP Publishing. https://doi.org/10.1088/1742$6596 / 1372 / 1 / 012064$

Ozmeric N (2004) Advances in periodontal disease markers. Clin Chim Acta 343(1-2):1-16. https://doi.org/10.1016/j.cccn.2004.01.022

Pal M, Berhanu G, Desalegn C, Kandi V (2020) Severe acute respiratory syndrome coronavirus-2 (SARS-CoV-2): An update. Cureus 12(3): e7423. https://doi.org/10.7759/cureus.7423

Paluszkiewicz C, Pięta E, Woźniak M, Piergies N, Koniewska A, Ścierski W, Misiołek M, Kwiatek WM (2020) Saliva as a first-line diagnostic tool: A spectral challenge for identification of cancer biomarkers. J Mol Liq 307:112961. https://doi.org/10.1016/j.molliq.2020.112961

Parlatan U, Inanc MT, Ozgor BY, Oral E, Bastu E, Unlu MB, Basar G (2019) Raman spectroscopy as a non-invasive diagnostic technique for endometriosis. Sci Rep 9. https://doi.org/10.1038/s41598-01956308-y

Pathiyil V, Udayasankar R (2019) Salivary Diagnostics. Saliva and Salivary Diagnostics, Intech. https://doi.org/10.5772/intechopen. 84722

Patil A, Choudhari KS, Unnikrishnan VK, Shenoy N, Ongole R, Pai KM, Kartha VB, Chidangil S (2013) Salivary protein markers: a noninvasive protein profile-based method for the early diagnosis of oral premalignancy and malignancy. J Biomed Opt 18(10):101317. https://doi.org/10.1117/1.JBO.18.10.101317

Patil A, Bhat S, Pai KM, Rai L, Kartha VB, Chidangil S (2015) Ultrasensitive high performance liquid chromatography-laser-induced fluorescence based proteomics for clinical applications. J Proteome 127:202-210. https://doi.org/10.1016/j.jprot.2015.05.006

Peungthum P, Sudprasert K, Amarit R, Somboonkaew A, Sutapun B, Vongsakulyanon A, Seedacoon W, Kitpoka P, Kunakorn M, Srikhirin T (2017) Surface plasmon resonance imaging for ABH antigen detection on red blood cells and in saliva: secretor statusrelated ABO subgroup identification. Analyst 142(9):1471-1481. https://doi.org/10.1039/C7AN00027H

Popp J, Tuchin VV, Chiou A, Heinemann SH (2011) Handbook of biophotonics: Vol. 2: Photonics for health care. John Wiley \& Sons

Pupeza I, Huber M, Trubetskov M, Schweinberger W, Hussain SA, Hofer C, Fritsch K, Poetzlberger M, Vamos L, Fill E (2020) Field-resolved infrared spectroscopy of biological systems. Nature 577(7788):52 59. https://doi.org/10.1038/s41586-019-1850-7

Qiu S, Xu Y, Huang L, Zheng W, Huang C, Huang S, Lin J, Lin D, Feng S, Chen R (2016) Non-invasive detection of nasopharyngeal carcinoma using saliva surface-enhanced Raman spectroscopy. Oncol Lett 11(1):884-890. https://doi.org/10.3892/ol.2015.3969

Qiu G, Gai Z, Tao Y, Schmitt J, Kullak-Ublick GA, Wang J (2020) Dualfunctional plasmonic photothermal biosensors for highly accurate severe acute respiratory syndrome coronavirus 2 detection. ACS nano 14(5):5268-5277. https://doi.org/10.1021/acsnano.0c02439
Quadras DD, Nayak UK, Kumari NS, Priyadarshini H, Gowda S, Fernandes B (2019) In vivo study on the release of nickel, chromium, and zinc in saliva and serum from patients treated with fixed orthodontic appliances. Dent Res J 16(4):209

Quinn AA, Elkins KM (2017) The differentiation of menstrual from venous blood and other body fluids on various substrates using ATR FT-IR spectroscopy. J Forensic Sci 62(1):197-204. https:// doi.org/10.1111/1556-4029.13250

Rani M, Marchesi C, Federici S, Rovelli G, Alessandri I, Vassalini I, Ducoli S, Borgese L, Zacco A, Bilo F (2019) Miniaturized NearInfrared (MicroNIR) Spectrometer in Plastic Waste Sorting. Materials 12(17):2740. https://doi.org/10.3390/ma12172740

Ray P, Steckl AJ (2019) Label-free optical detection of multiple biomarkers in sweat, plasma, urine, and saliva. ACS Sens 4(5):1346 1357. https://doi.org/10.1021/acssensors.9b00301

Riedel T, Surman F, Hageneder S, Pop-Georgievski O, Noehammer C, Hofner M, Brynda E, Rodriguez-Emmenegger C, Dostalek J (2016) Hepatitis B plasmonic biosensor for the analysis of clinical serum samples. Biosens Bioelectron 85:272-279. https://doi.org/10.1016/ j.bios.2016.05.014

Riedel T, Hageneder S, Surman F, Pop-Georgievski O, Noehammer C, Hofner M, Brynda E, Rodriguez-Emmenegger C, Dostalek J (2017) Plasmonic hepatitis B biosensor for the analysis of clinical saliva. Anal.Chem. 89(5):2972-2977. https://doi.org/10.1021/acs. analchem.6b04432

Roblegg E, Coughran A, Sirjani D (2019) Saliva: An all-rounder of our body. Eur J Pharm Biopharm 142:133-141. https://doi.org/10.1016/ j.ejpb.2019.06.016

Rodrigues LM, Magrini TD, Lima CF, Scholz J, da Silva Martinho H, Almeida JD (2017) Effect of smoking cessation in saliva compounds by FTIR spectroscopy. Spectrochim Acta, Part A 174: 124-129. https://doi.org/10.1016/j.saa.2016.11.009

Rodrigues LM, Alva TDM, da Silva Martinho H, Almeida JD (2019a) Analysis of saliva composition in patients with burning mouth syndrome (BMS) by FTIR spectroscopy. Vib Spectrosc 100:195-201. https://doi.org/10.1016/j.vibspec.2018.12.002

Rodrigues RP, Aguiar EM, Cardoso-Sousa L, Caixeta DC, Guedes CC, Siqueira WL, Maia YCP, Cardoso SV, Sabino-Silva R (2019b) Differential molecular signature of human saliva using ATR-FTIR spectroscopy for chronic kidney disease diagnosis. Braz Dent J 30(5):437-445. https://doi.org/10.1590/0103-6440201902228

Saranya KKN (2017) Molecular Signatures in Infrared Spectra of Saliva in Healthy, Chronic and Aggressive Periodontitis Masters, Tamilnadu Dr. MGR medical university.111: https://doi.org/10. 1016/j.vibspec.2020.103179.

Seredin P, Goloshchapov D, Ippolitov Y, Vongsvivut P (2018) Pathology-specific molecular profiles of saliva in patients with multiple dental caries - potential application for predictive, preventive and personalised medical services. EPMA J 9(2):195-203. https:// doi.org/10.1007/s13167-018-0135-9

Shah S (2018) Salivaomics: The current scenario. Journal of oral and maxillofacial pathology: JOMFP 22(3):375. https://doi.org/10. 4103/jomfp.JOMFP_171_18

Shameem KM, Tamboli M, Devangad P, Unnikrishnan V, George SD, Kartha V, Santhosh C (2017) Conventional and standoff pulsed laser-Raman-echelle-time-gated (PRET) system. J Raman Spectrosc 48(6):785-788. https://doi.org/10.1002/jrs.5125

Shang J, Ye G, Shi K, Wan Y, Luo C, Aihara H, Geng Q, Auerbach A, Li F (2020) Structural basis of receptor recognition by SARS-CoV-2. Nature. 581(7807):221-224. https://doi.org/10.1038/s41586-0202179-y

Shende C, Inscore F, Maksymiuk P, Farquharson S (2005) Ten-minute analysis of drugs and metabolites in saliva by surface-enhanced Raman spectroscopy. In: Smart Medical and Biomedical Sensor Technology III, International Society for Optics and Photonics. 
Boston, MA, United States, p 6007. https://doi.org/10.1117/12. 633281

Shende C, Huang H, Farquharson S (2014) Detection of illicit drugs in impaired driver saliva by a field-usable SERS analyzer. In: Smart Biomedical and Physiological Sensor Technology XI, International Society for Optics and Photonics.9107. Maryland, United States. https://doi.org/10.1117/12.2054284

Shende C, Brouillette C, Farquharson S (2019) Detection of codeine and fentanyl in saliva, blood plasma and whole blood in 5-minutes using a SERS flow-separation strip. Analyst. 144(18):5449-5454. https:// doi.org/10.1039/C9AN01087D

Shimokawa T, Ishii T, Takahashi Y, Mitani Y, Mifune H, Chubachi S, Satoh M, Oba Y, Adachi K, Sugawara S (2019) Development of multi-directional functional near-infrared spectroscopy system for human neuroimaging studies. Biomed Opt Express 10(3):13931404. https://doi.org/10.1364/BOE.10.001393

Sikirzhytski V, Sikirzhytskaya A, Lednev IK (2012) Multidimensional Raman spectroscopic signature of sweat and its potential application to forensic body fluid identification. Anal Chim Acta 718:78-83. https://doi.org/10.1016/j.aca.2011.12.059

Simsek Ozek N, Zeller I, Renaud D, Gümüș P, Nizam N, Severcan F, Buduneli N, Scott D (2016) Differentiation of chronic and aggressive periodontitis by FTIR spectroscopy. J Dent Res 95(13):14721478. https://doi.org/10.1177/0022034516663696

Singh AK, Jha SK (2019) Fabrication and validation of a handheld noninvasive, optical biosensor for self-monitoring of glucose using saliva. IEEE SensJ 19(18):8332-8339. https://doi.org/10.1109/JSEN. 2019.2920296

Sivashanmugan K, Squire K, Tan A, Zhao Y, Kraai JA, Rorrer GL, Wang AX (2019a) Trace detection of tetrahydrocannabinol in body fluid via surface-enhanced Raman scattering and principal component analysis. ACS Sens 4(4):1109-1117. https://doi.org/10.1021/ acssensors.9b00476

Sivashanmugan K, Zhao Y, Wang AX (2019b) Tetrahydrocannabinol Sensing in Complex Biofluid with Portable Raman Spectrometer Using Diatomaceous SERS Substrates. Biosensors 9(4):125. https://doi.org/10.3390/bios9040125

Sonny S, Sesay AM, Virtanen V (2010) Development of diagnostic SPR based biosensor for the detection of pharmaceutical compounds in saliva. Laser Applications in Life Sciences, International Society for Optics and Photonics. Oulu, Finland 7376. https://doi.org/10.1117/ 12.871116

Spyratou E, Makropoulou M, Mourelatou E, Demetzos C (2012) Biophotonic techniques for manipulation and characterization of drug delivery nanosystems in cancer therapy. Cancer Lett 327(12):111-122. https://doi.org/10.1016/j.canlet.2011.12.039

Srinivasan M, Zunt SL, Goldblatt LI (2020) Oral epithelial expression of angiotensin converting enzyme-2: Implications for COVID-19 diagnosis and prognosis. https://doi.org/10.1101/2020.06.22.165035

Stevens RC, Soelberg SD, Near S, Furlong CE (2008) Detection of cortisol in saliva with a flow-filtered, portable surface plasmon resonance biosensor system. Anal Chem 80(17):6747-6751. https://doi. org/10.1021/ac800892h

Su K-Y, Lee W-L (2020) Fourier Transform Infrared Spectroscopy as a Cancer Screening and Diagnostic Tool: A Review and Prospects. Cancers 12(1):115. https://doi.org/10.3390/cancers12010115

Su M, Jiang Y, Yu F, Yu T, Du S, Xu Y, Yang L, Liu H (2019) Mirrorlike Plasmonic Capsules for Online Microfluidic Raman Analysis of Drug in Human Saliva and Urine. ACS Appl Bio Mater 2(9): 3828-3835. https://doi.org/10.1021/acsabm.9b00425

Sultana RR, Zafarullah S, Kirubamani NH (2011) Utility of FTIR spectroscopic analysis of saliva of diabetic pregnant women in each trimester. Indian J Sci Technol 4(8):967-970. https://doi.org/10. 17485/ijst\%2F2011\%2Fv4i8\%2F30905

Sun Y, Xu L, Zhang F, Song Z, Hu Y, Ji Y, Shen J, Li B, Lu H, Yang H (2017) A promising magnetic SERS immunosensor for sensitive detection of avian influenza virus. Biosens Bioelectron 89:906912. https://doi.org/10.1016/j.bios.2016.09.100

Tahara Y, Huang Z, Kiritoshi T, Onodera T, Toko K (2014) Development of indirect competitive immuno-assay method using SPR detection for rapid and highly sensitive measurement of salivary cortisol levels. Front bioeng biotechnol 2:15. https://doi.org/10.3389/fbioe. 2014.00015

Takamura A, Watanabe K, Akutsu T, Ozawa T (2018) Soft and robust identification of body fluid using Fourier transform infrared spectroscopy and chemometric strategies for forensic analysis. Sci Rep 8(1):1-10. https://doi.org/10.1038/s41598-018-26873-9

Tan W, Sabet L, Li Y, Yu T, Klokkevold PR, Wong DT, Ho C-M (2008) Optical protein sensor for detecting cancer markers in saliva. Biosens Bioelectron 24(2):266-271. https://doi.org/10.1016/j.bios. 2008.03.037

To KK, Lu L, Yip CC, Poon RW, Fung AM, Cheng A, Lui DH, Ho DT, Hung IF, Chan K-H (2017) Additional molecular testing of saliva specimens improves the detection of respiratory viruses. Emerging Microbes Infect 6(1):1-7. https://doi.org/10.1038/emi.2017.35

To KK-W, Yip C, Lai C, Wong C, Ho D, Pang P, Ng A, Leung K-H, Poon R, Chan K-H (2019) Saliva as a diagnostic specimen for testing respiratory virus by a point-of-care molecular assay: a diagnostic validity study. Clin Microbiol Infect 25(3):372-378. https://doi.org/ 10.1016/j.cmi.2018.06.009

To KK-W, Tsang OT-Y, Leung W-S, Tam AR, Wu T-C, Lung DC, Yip CC-Y, Cai J-P, Chan JM-C, Chik TS-H (2020a) Temporal profiles of viral load in posterior oropharyngeal saliva samples and serum antibody responses during infection by SARS-CoV-2: an observational cohort study. Lancet Infect Dis 20(5):565-574. https://doi. org/10.1016/S1473-3099(20)30196-1

To KK-W, Tsang OT-Y, Yip CC-Y, Chan K-H, Wu T-C, Chan JM-C, Leung W-S, Chik TS-H, Choi CY-C, Kandamby DH (2020b) Consistent detection of 2019 novel coronavirus in saliva. Clin Infect Dis 71(15):841-843. https://doi.org/10.1093/cid/ciaa149

Tuschel D (2018) Exploring resonance Raman spectroscopy. Spectrosopy. 33(12):12-19

Virkler K, Lednev IK (2010) Forensic body fluid identification: the Raman spectroscopic signature of saliva. Analyst. 135(3):512517. https://doi.org/10.1039/B919393F

Wallace J (2019) "Laser Focus World's top 20 photonics technology picks for 2019." Laser Focus World, from https://www. laserfocusworld.com/home/article/14072039/

Wallace J (2020) "New 'saliva test' to instantly detect coronavirus with lasers." Test and Measurement, Laser Focus World, https://www. laserfocusworld.com/test-measurement/article/14173589/newsaliva-test-to-instantly-detect-coronavirus-via-interferometric-lasertechnology

Wang W-K, Chen S-Y, Liu I-J, Chen Y-C, Chen H-L, Yang C-F, Chen PJ, Yeh S-H, Kao C-L, Huang L-M (2004) "Detection of SARSassociated coronavirus in throat wash and saliva in early diagnosis." Emerging Infect. Dis. 10(7):1213-1219. https://doi.org/10.3201/ eid1007.031113

Wang A, Wang CP, Tu M, Wong DT (2016) Oral biofluid biomarker research: current status and emerging frontiers. Diagnostics 6(4):45. https://doi.org/10.3390/diagnostics6040045

Wang C, Meloni MM, Wu X, Zhuo M, He T, Wang J, Wang C, Dong P (2019) Magnetic plasmonic particles for SERS-based bacteria sensing: A review. AIP Adv 9(1):010701. https://doi.org/10.1063/1. 5050858

Wang Q, Zhang Y, Wu L, Niu S, Song C, Zhang Z, Lu G, Qiao C, Hu Y, Yuen K-Y (2020) Structural and functional basis of SARS-CoV-2 entry by using human ACE2. Cell 181(4):894-904.e9. https://doi. org/10.1016/j.cell.2020.03.045

Wasik D, Mulchandani A, Yates MV (2018) Salivary detection of dengue virus NS1 protein with a label-free immunosensor for early dengue diagnosis. Sensors 18(8):2641. https://doi.org/10.3390/s18082641 
Wood BR, Hammer L, McNaughton D (2005) Resonance Raman spectroscopy provides evidence of heme ordering within the functional erythrocyte. Vib Spectrosc 38(1-2):71-78. https://doi.org/10.1016/j. vibspec.2005.02.016

Xu H, Zhong L, Deng J, Peng J, Dan H, Zeng X, Li T, Chen Q (2020a) High expression of ACE2 receptor of 2019-nCoV on the epithelial cells of oral mucosa. Int J Oral Sci 12(1):1-5. https://doi.org/10. 1038/s41368-020-0074-X

Xu J, Li Y, Gan F, Du Y, Yao Y (2020b) Salivary glands: potential reservoirs for COVID-19 asymptomatic infection. J Dent Res 99(8):989-989. https://doi.org/10.1177/0022034520918518

Xu R, Cui B, Duan X, Zhang P, Zhou X, Yuan Q (2020c) Saliva: potential diagnostic value and transmission of 2019-nCoV. Int J Oral Sci 12(1):1-6. https://doi.org/10.1038/s41368-020-0080-z

Yacaman MJ, Keim P, Wagner D, Kellar R, Koppisch A (2020) "Development of a New Test for SARS-CoV-2 using Single Molecule Surface Enhanced Raman Spectroscopy." National Science Foundation, Where Discoveries Begin https://www.nsf. gov/a w a d s e a r ch/s how A w a rd? A W D_ I D = 2030488\&HistoricalAwards=false. $\mid$

Yang Y, Gao W (2019) Wearable and flexible electronics for continuous molecular monitoring. Chem Soc Rev 48(6):1465-1491. https://doi. org/10.1039/C7CS00730B

Yang C-Y, Brooks E, Li Y, Denny P, Ho C-M, Qi F, Shi W, Wolinsky L, Wu B, Wong DT (2005) Detection of picomolar levels of interleukin-8 in human saliva by SPR. Lab Chip 5(10):1017-1023. https://doi.org/10.1039/B504737D

Yang T, Guo X, Wang H, Fu S, Yang H (2015) Magnetically optimized SERS assay for rapid detection of trace drug-related biomarkers in saliva and fingerprints. Biosens.Bioelectron. 68:350-357. https:// doi.org/10.1016/j.bios.2015.01.021

Yap X-L, Ong T-A, Lim J, Wood B, Lee W-L (2019) Study of prostate cancer-derived extracellular vesicles in urine using IR spectroscopy. Progress in Drug Discovery \& Biomedical Science 2(1). https://doi. org/10.36877/pddbs.a0000026

Yeh Y-T, Gulino K, Zhang Y, Sabestien A, Chou T-W, Zhou B, Lin Z, Albert I, Lu H, Swaminathan V (2020) A rapid and label-free platform for virus capture and identification from clinical samples. Proc Natl Acad Sci U S A 117(2):895-901. https://doi.org/10.1073/pnas. 1910113117

Yunanto A, Iskandar AA, Utama N, Muthmainnah, Suhartono E (2019) Early detection of neonatal sepsis using fourier transformation infrared spectroscopy (FTIR). AIP Conference Proceedings, AIP Publishing LLC 2108(1). https://doi.org/10.1063/1.5110001

Yuvaraj M, Udayakumar K, Jayanth V, Rao AP, Bharanidharan G, Koteeswaran D, Munusamy BD, Ganesan S (2014) Fluorescence spectroscopic characterization of salivary metabolites of oral cancer patients. J Photochem Photobiol B 130(5):153-160. https://doi.org/ 10.1016/j.jphotobiol.2013.11.006

Yuvaraj M, Aruna P, Koteeswaran D, Muthuvelu K, Ganesan S (2018) UV-native fluorescence steady and excited state kinetics of salivary protein of normal subjects, oral premalignant and malignant conditions. J Lumin 196:236-243. https://doi.org/10.1016/j.jlumin.2017. 12.024

Zahroh A, Nasution AM, Suyanto H (2019) The analysis of calcium contained in saliva due to smoking habits: using laser-induced breakdown spectroscopy (LIBS). In: Third International Seminar on Photonics, Optics, and Its Applications (ISPhOA 2018), International Society for Optics and Photonics.11044. Surabaya, Indonesia. https://doi.org/10.1117/12.2504816

Zamora-Mendoza B, Espinosa-Tanguma R, Ramirez-Elias M, CabreraAlonso R, Montero-Moran G, Portales-Perez D, Rosales-Romo J, Gonzalez J, Gonzalez C (2019) Surface-enhanced raman spectroscopy: a non invasive alternative procedure for early detection in childhood asthma biomarkers in saliva. Photodiagn Photodyn Ther 27:85-91. https://doi.org/10.1016/j.pdpdt.2019.05.009

Zaorska E, Konop M, Ostaszewski R, Koszelewski D, Ufnal M (2018) Salivary Hydrogen Sulfide Measured with a New Highly Sensitive Self-Immolative Coumarin-Based Fluorescent Probe. Molecules 23(9):2241. https://doi.org/10.3390/molecules23092241

Zapata F, de la Ossa MÁF, García-Ruiz C (2015) Emerging spectrometric techniques for the forensic analysis of body fluids. Trends Anal Chem 64:53-63. https://doi.org/10.1016/j.trac.2014.08.011

Zhang C-Z, Cheng X-Q, Li J-Y, Zhang P, Yi P, Xu X, Zhou X-D (2016) Saliva in the diagnosis of diseases. Int J Oral Sci 8(3):133-137. https://doi.org/10.1038/ijos.2016.38

Zhang X-Y, Zhang P-Y, Aboul-Soud MA (2017) From inflammation to gastric cancer: Role of Helicobacter pylori. Oncol Lett 13(2):543548. https://doi.org/10.3892/ol.2016.5506

Zhang Y, Mi X, Tan X, Xiang R (2019) Recent progress on liquid biopsy analysis using surface-enhanced Raman spectroscopy. Theranostics 9(2):491-525. https://doi.org/10.7150/thno.29875

Zlotogorski-Hurvitz A, Dekel BZ, Malonek D, Yahalom R, Vered M (2019) FTIR-based spectrum of salivary exosomes coupled with computational-aided discriminating analysis in the diagnosis of oral cancer. J Cancer Res Clin Oncol 145(3):685-694. https://doi.org/10. 1007/s00432-018-02827-6

Žukovskaja O, Jahn IJ, Weber K, Cialla-May D, Popp J (2017) Detection of Pseudomonas aeruginosa metabolite pyocyanin in water and saliva by employing the SERS technique. Sensors 17(8):1704. https:// doi.org/10.3390/s17081704

Publisher's note Springer Nature remains neutral with regard to jurisdictional claims in published maps and institutional affiliations. 